\title{
PRESENCIA DEL INCA EN YOCAVIL ICATAMARCA, ARGENTINA). INTEGRACIÓN EN LA DIVERSIDAD
}

\author{
INCA PRESENCE IN YOCAVIL (CATAMARCA, ARGENTINA). INTEGRATION \\ IN DIVERSITY
}

\author{
Myriam Tarragóa ${ }^{A}$ Marina Marchegiani ${ }^{B}$, Valeria Palamarczuk ${ }^{C} \&$ Alejandra Reynoso
}

Se ofrece una síntesis sobre las particularidades de la presencia incaica en el sur de Yocavil (Catamarca, Argentina), ponderando las características de las instalaciones imperiales, la alfarería incaica que circuló en la región y la relevancia del Qhapaq Ñan como eje integrador. Esta síntesis integra nueva información sobre instalaciones relevantes como El Calvario de Fuerte Quemado y Punta de Balasto. Se reflexiona sobre las características de las interacciones entre las sociedades locales y el Estado incaico en expansión, privilegiando el estudio de los procesos de cambio a partir de la posición de las sociedades dominadas.

Palabras clave: Noroeste Argentino, valle de Yocavil, sistema vial incaico, arquitectura, alfarería Inca Provincial.

This is a synthesis on the main features of the Inca presence in area of southern Yocavil (Catamarca, Argentina), that considers imperial settings, Inca pottery that circulated in the region and the relevance of Qhapaq Nan as an integrating axis. This synthesis includes new information regarding relevant settings such as El Calvario de Fuerte Quemado and Punta de Balasto. There is a reflection on the characteristics of interactions between local societies and the expanding Inca State, focusing on the study of the processes of change from the position of dominated societies.

Keywords: Argentine Northwest, Yocavil valley, Inca Road system, architecture, Inca Provincial pottery.

\section{INTRODUCCIÓN}

El desarrollo del Estado Inca constituye uno de los procesos históricos más fascinantes de la América precolombina. Según las fuentes escritas y las evidencias arqueológicas, tres cualidades sobresalientes fueron su gran extensión, la rapidez de la expansión y la organización política alcanzada. El papel del Qhapaq Ñan (Camino Inca) fue crucial en estos tres aspectos. Se trata de una obra física única y una de las entidades más masivas que se haya construido en los Estados antiguos. Fue planificada para unir espacios económicos, sociales, culturales y sagrados a lo largo de $c a .26 .000 \mathrm{~km}$ de ruta atravesando la cordillera más grande y elevada de América. Las habilidades constructivas aumentan la excepcionalidad de la empresa. Eje central del proyecto político Inca, constituye la síntesis de los caminos utilizados a lo largo de más de dos mil años de historia de las sociedades andinas (Strube Erdmann 1963; Hyslop 1984).

El desarrollo de la red vial fue entrelazando lugares y poblaciones con variadas lenguas y tradiciones, con

A Myriam Tarragó, Universidad de Buenos Aires, Instituto de las Culturas (IDECU) UBA - CONICET, Facultad de Filosofía y Letras, Museo Etnográfico Juan B. Ambrosetti. Moreno 350 (1091), CABA, Argentina, email: tarragomyriam@gmail.com

B Marina Marchegiani, Museo Etnográfico Juan B. Ambrosetti. Moreno 350 (1091), CABA, Argentina, email: marinamarchegiani@yahoo.com.ar

c Valeria Palamarczuk, Universidad de Buenos Aires, Instituto de las Culturas (IDECU) uba - COnICET, Facultad de Filosofía y Letras, Museo Etnográfico Juan B. Ambrosetti. Moreno 350 (1091), CABA, Argentina, email: valepala@yahoo.com.ar

D Alejandra Reynoso, Museo Etnográfico Juan B. Ambrosetti. Moreno 350 (1091), CABA, Argentina, email: ad_reynoso@yahoo.com.ar Recibido: diciembre 2015. Aceptado: mayo 2016. 
lo que propició una integración en la diversidad. Este proceso puede abordarse desde el núcleo político que propendía a la integración mediante el pacto con sectores locales o la violencia militar y desde la diversidad de los pueblos de la periferia que nunca antes habían formado parte de un gran Estado.

Para mejorar la comprensión de estos procesos que se desarrollaron en una escala espacial sorprendente es fundamental seguir estudiando la red vial cada vez con mayor precisión incorporando nuevos tramos. Al mismo tiempo, es necesario indagar la diversidad cultural -material e inmaterial- de los pueblos que quedaron incluidos dentro del Estado Inca. Los dos indicadores que consideramos más aptos, dada su ubicuidad en los sitios arqueológicos, son la arquitectura de las instalaciones anexas o vinculadas al camino y las variedades estilísticas en los bienes de uso que circularon en la época. Uno de los materiales más ricos en información es la alfarería Inca Provincial.

Desde el punto de vista metodológico, es crucial acudir a las fuentes lingüísticas, históricas y arqueológicas a través de una lectura crítica.

La imposición del quechua (runa simi) como idioma oficial contribuyó en forma sustantiva a la vertebración del Imperio y al funcionamiento del gobierno, dado que servía como medio de comunicación sobre las numerosas lenguas que se hablaban desde el sur de la actual Colombia hasta Chile y Argentina. Una indagación que se ha hecho en forma muy limitada es el estudio de los topónimos y los antropónimos en el kakan de los diaguitas (Nardi 1979). Por su parte, las fuentes escritas son muy ricas para los Andes centrales, pero su número y especificidad van disminuyendo hacia el sur. Tan es así que podríamos plantear una opacidad en las síntesis que circulan sobre el Estado Inca, sin casi ninguna referencia a los Andes meridionales (cf. Patterson 1992: 170; Stingl 2007: 419).

No obstante, las fuentes arqueológicas son contundentes en cuanto a las señales materiales del Estado Inca y nos permiten penetrar en ese pasado a través de los vestigios arquitectónicos y los múltiples bienes muebles que se conservan (Raffino 1981; Williams 2004). La circulación de producciones materiales y de recursos, como de bienes simbólicos e intangibles, llegó mucho más allá de las fronteras estrictas del Estado (Pärssinen 1992: 139).

Como una contribución a estos objetivos de investigación, presentamos como caso de estudio un tramo de $42 \mathrm{~km}$ de la red troncal en el Noroeste Argentino (NOA), cubierta hoy en gran parte por la Ruta Nacional No 40 , que se emplaza en la parte meridional del valle Yocavil, entre Fuerte Quemado y Punta de Balasto, Departamento Santa María, Provincia de Catamarca. Se discuten las instalaciones vinculadas y el material cultural diagnóstico de la época (fig. 1).

Las fuentes escritas del siglo XVI son escasas para el NOA. Sin embargo, pueden rastrearse determinados signos como para tratar de comprender la singularidad de esta región en su integración. Las provincias incaicas Xibixuy, Chicoana y Quirequire, aparecen mencionadas en los documentos de las primeras entradas de los españoles por el norte, Diego de Almagro en 1536 (Fernández de Oviedo y Valdés 1851-1855: 264), Diego de Rojas en 1543 (González de Prado 1548) y el itinerario de Matienzo (1566), entre otros (Tarragó 1984). Según las referencias a lugares y su correlación con localidades actuales, la región de Yocavil correspondería al inicio septentrional de la provincia de Quirequire, en los confines de Chicoana. Estas áreas habrían sido muy importantes para el abastecimiento de comida y de bastimentos para Diego de Almagro, dado que allí paró varios meses esperando que se abriera la ruta o "puerto de nieve" hacia la provincia de Copayapo, en Copiapó, Chile. El itinerario bastante temprano del oidor Matienzo (1566), en búsqueda de una salida a los productos coloniales, también nos ayuda a desbrozar la importancia de los valles Calchaquíes como parte troncal del Camino Principal Andino (Strube Erdmann 1958; Vitry 2007). Por ende, la sucesión de sitios y las evidencias del Inca en Yocavil resultan sustantivos por encontrarse a la vera de la red troncal del Qhapaq Ñan.

Se propone aquí un recorrido que sigue un rumbo de norte a sur por algunos de los sectores con evidencias incaicas, arquitectónicas y artefactuales, destacando las particularidades observadas en la región.

\section{FUERTE QUEMADO}

El área de Fuerte Quemado ha sido tempranamente destacada en las investigaciones de las sociedades prehispánicas de Yocavil. Su riqueza y complejidad arqueológica la convierten en una zona clave para la comprensión de los procesos sociales tanto de los desarrollos tardíos locales como de los momentos de ocupación incaica en la región. Para esos tiempos se 


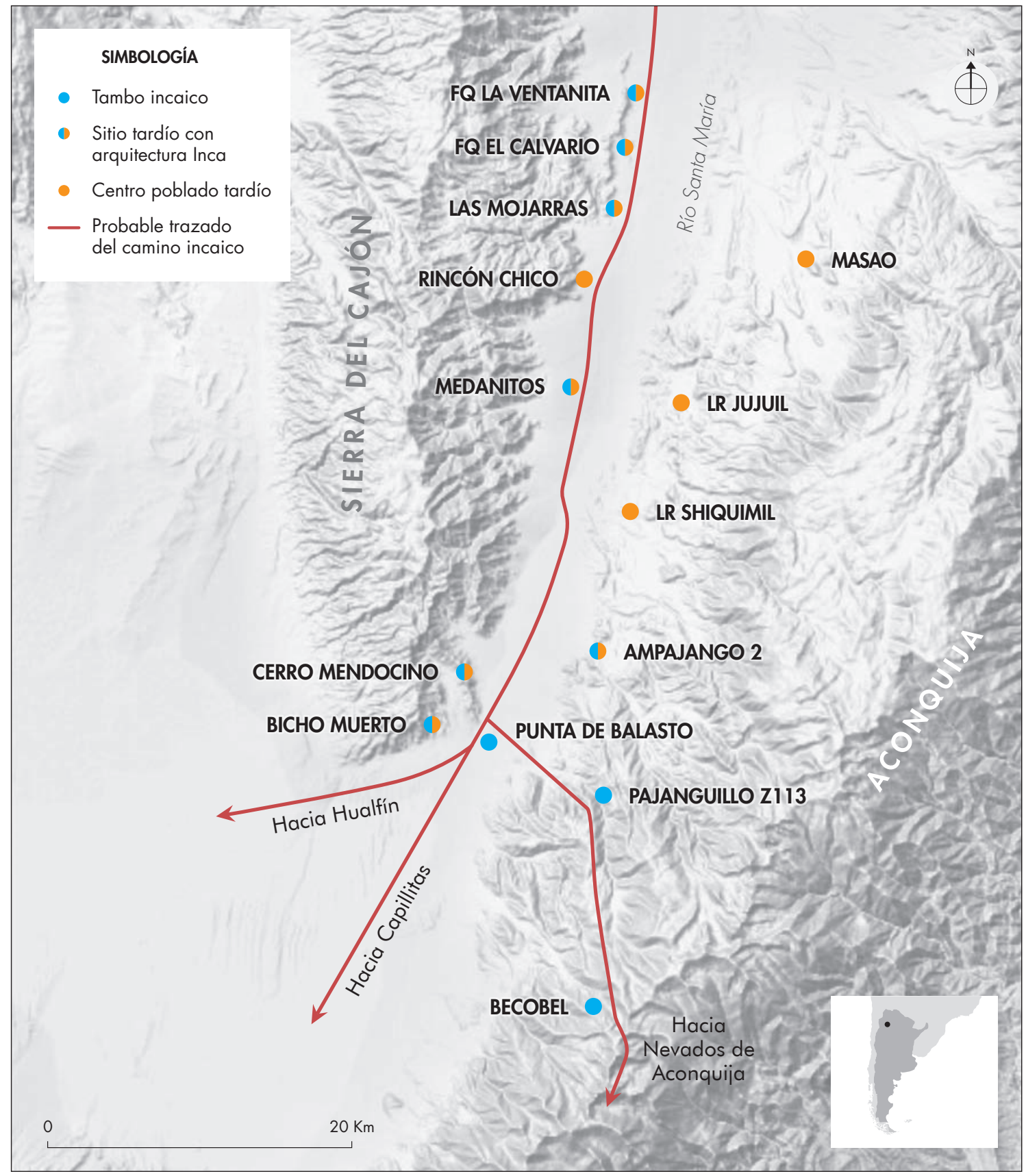

Figura 1. Mapa del área de Yocavil con indicación de los sitios mencionados en el texto. Figure 1. Map of the Yocavil area indicating places mentioned in the text.

presentan tres grandes zonas arqueológicas de norte a sur: La Ventanita, El Socavón y El Calvario (fig. 2).

En el límite actual de la Provincia de Catamarca con la Provincia de Tucumán se emplaza el poblado conocido como La Ventanita o Intihuatana, que incluye una configuración tipo pukara en la cumbre y ladera de un espolón rocoso, así como varias instalaciones distribuidas sobre el piedemonte (Lafone Quevedo 1902; Bruch 1911; Kriscautzky 1999). Kriscautzky (1999) definió en este asentamiento siete sectores. El 


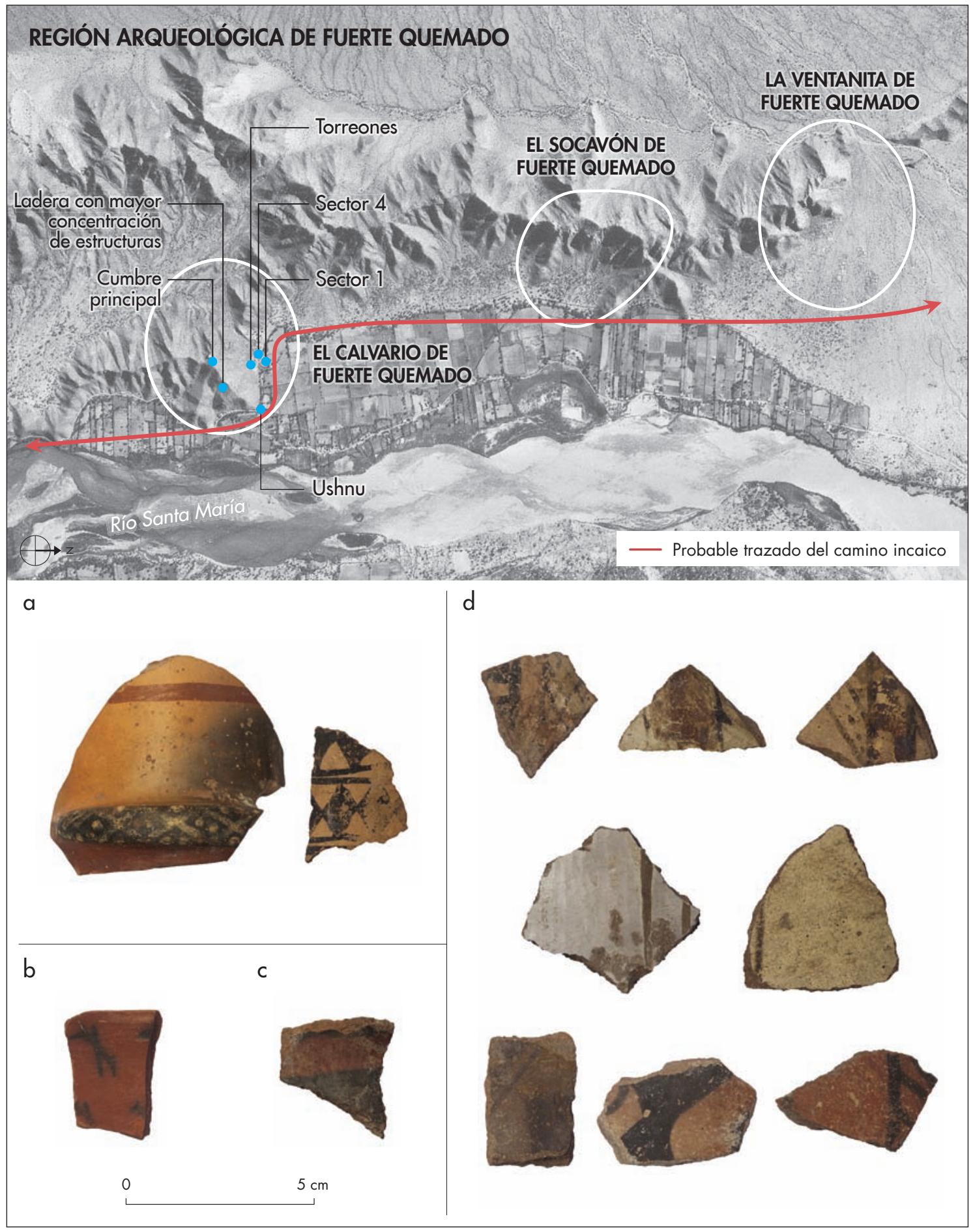

Figura 2. Superior: región arqueológica de Fuerte Quemado. Inferior: selección de fragmentos de distintos tipos de cerámica inca con decoración pintada recuperados en El Calvario de Fuerte Quemado (superficie): a) pie de ladera norte, Sector 4; b) Ushnu; c) cumbre principal, Sector 6; d) bajo circundante ladera norte, Sector 1. Figure 2. Above: Fuerte Quemado archaeological region. Below: selected fragments of several types of Inca pottery with painted decoration recovered from El Calvario de Fuerte Quemado (surface): a) north face, foothill, Sector 4; b) Ushnu; c) main summit, Sector 6; d) lower surrounding area north face, Sector 1. 
sector IV corresponde a una instalación de arquitectura incaica emplazada a la vera del Camino Inca. Presenta estructuras cuadrangulares, rectangulares y algunas circulares definidas como collcas. Las estructuras están conformadas por paredes de pirca doble con argamasa y revoque, de 60 a $80 \mathrm{~cm}$ de ancho, y presentan pisos preparados de barro arcilloso y aberturas de forma trapezoidal. En las excavaciones se recuperó cerámica Inca en las formas de aríbalos, aribaloides y ollas con pie (Orgaz 2012). También se hallaron escorias y restos de moldes incisos, un hacha de bronce y crisoles utilizados en la producción de objetos de bronce (Kriscautzky 1999: 128-129). La cerámica incaica también está presente en sectores locales, tanto en contextos domésticos (Sector v) como funerarios (Sector I) (Orgaz 2014).

Tres kilómetros hacia el sur se ubica El Calvario de Fuerte Quemado, un pukara construido sobre un cerro de múltiples espolones, sus laderas y bajo circundante (Quiroga 1901; Reynoso et al. 2010). En la década de 1960 se formalizó sobre este sitio el calvario católico actual, obra que impacta en áreas relevantes del poblado antiguo.

El asentamiento ocupa una superficie de 60 ha aproximadamente. Se registró un total de 489 estructuras arquitectónicas, de las cuales 184 corresponden a recintos, 54 a posibles recintos y 41 a plataformas (las estructuras restantes son líneas indeterminadas de muros dobles y simples). La arquitectura del poblado se basa en la técnica de construcción tardía local, de muro doble (más de $1 \mathrm{~m}$ de ancho) con relleno de ripio. Este sitio fue ocupado y modificado por los incas en sectores acotados como son la cumbre principal, la ladera norte y su bajo circundante y un área al pie de la conjunción de las laderas norte y este, en donde se emplaza el ushnu. En dichos sectores con arquitectura incaica también se recuperaron fragmentos cerámicos de diversos tipos incaicos (fig. 2).

La cumbre principal está constituida por un área circular irregular nivelada. Allí se registró un recinto rectangular de arquitectura inca, de $5 \times 3 \mathrm{~m}$ de lado aproximadamente, con muros dobles sin relleno de $55 \mathrm{~cm}$ de ancho promedio. En esta cumbre se habrían ubicado otros dos recintos de características similares (Quiroga 1901: 240-241).

Ya en el bajo, el ushnu está emplazado muy probablemente a la vera del antiguo Camino Inca. Está conformado por un gran montículo rocoso modificado artificialmente. En su lado occidental pueden aún observarse al menos tres líneas de muros conformando niveles aterrazados. En el sector oriental, al pie del montículo, también se registraron varios relictos de muros de contención. La estructura ocupa un área aproximada de $35 \times 20 \mathrm{~m}$, superando una altura de $6 \mathrm{~m}$. En superficie se han recuperado fragmentos de distintos tipos de cerámica incaica, entre ellos un fragmento de plato Inca Pacajes (fig. 2b).

Por último, en la ladera norte del centro poblado se ubican construcciones incaicas únicas en la región. Se trata de tres "torres" circulares de entre 3 y $4 \mathrm{~m}$ de diámetro, que según antiguas observaciones poseían más de $2 \mathrm{~m}$ de altura (Quiroga 1901: 236). Las estructuras, denominadas Torreones Superior, Medio e Inferior, están constituidas por muros dobles sin relleno e hiladas unidas con barro. Presentaban pisos limo-arcillosos consolidados sobre empedrados de lajas (figs. 3 y 4). Aunque solo se registró revoque interno en uno de los torreones, se trataría de una característica común a los tres (Quiroga 1901). Los fechados obtenidos reafirman su temporalidad vinculada a la ocupación incaica: $340 \pm$ 50 AP (LP1903) (Cal. 2 sigma 1459 (95,4\%)1665 DC) y $400 \pm 50$ AP (LP2044) (Cal. 2 sigma 1450 (95,4\%) 1634). ${ }^{1}$

Las excavaciones en área realizadas en los tres torreones permitieron recuperar un acontecimiento extremadamente significativo para comprender la interacción particular entre los representantes estatales y la población local. Para construir el Torreón Inferior, los incas destruyeron una estructura funeraria local, redepositando parte de su contenido bajo el piso de la nueva estructura. En íntima vinculación con este acontecimiento, se destaca la abundancia de vasijas locales rotas y dispersas bajo el piso del Torreón Medio, entre ellas más de 40 pucos cuyos fragmentos remontaron en un alto porcentaje (en algunos casos hasta el $35 \mathrm{o}$ $40 \%$ del total de la pieza). Este sería el caso más claro de violencia ejercida por los Incas en Yocavil, manifestado a partir de la destrucción de una tumba local de características diferenciales. Este tipo de prácticas también ha sido documentado en otros puntos del sur del imperio, como por ejemplo Los Amarillos en la Quebrada de Humahuaca (Nielsen \& Walker 1999) y Turi en la puna de Atacama (Aldunate et al. 2003).

\section{LAS MOJARRAS-RINCÓN CHICO}

El poblado alto de Las Mojarras denominado "Cerro Pintado" corresponde, por su visibilidad y protección 


\section{EL CALVARIO DE FUERTE QUEMADO TORREÓN SUPERIOR}
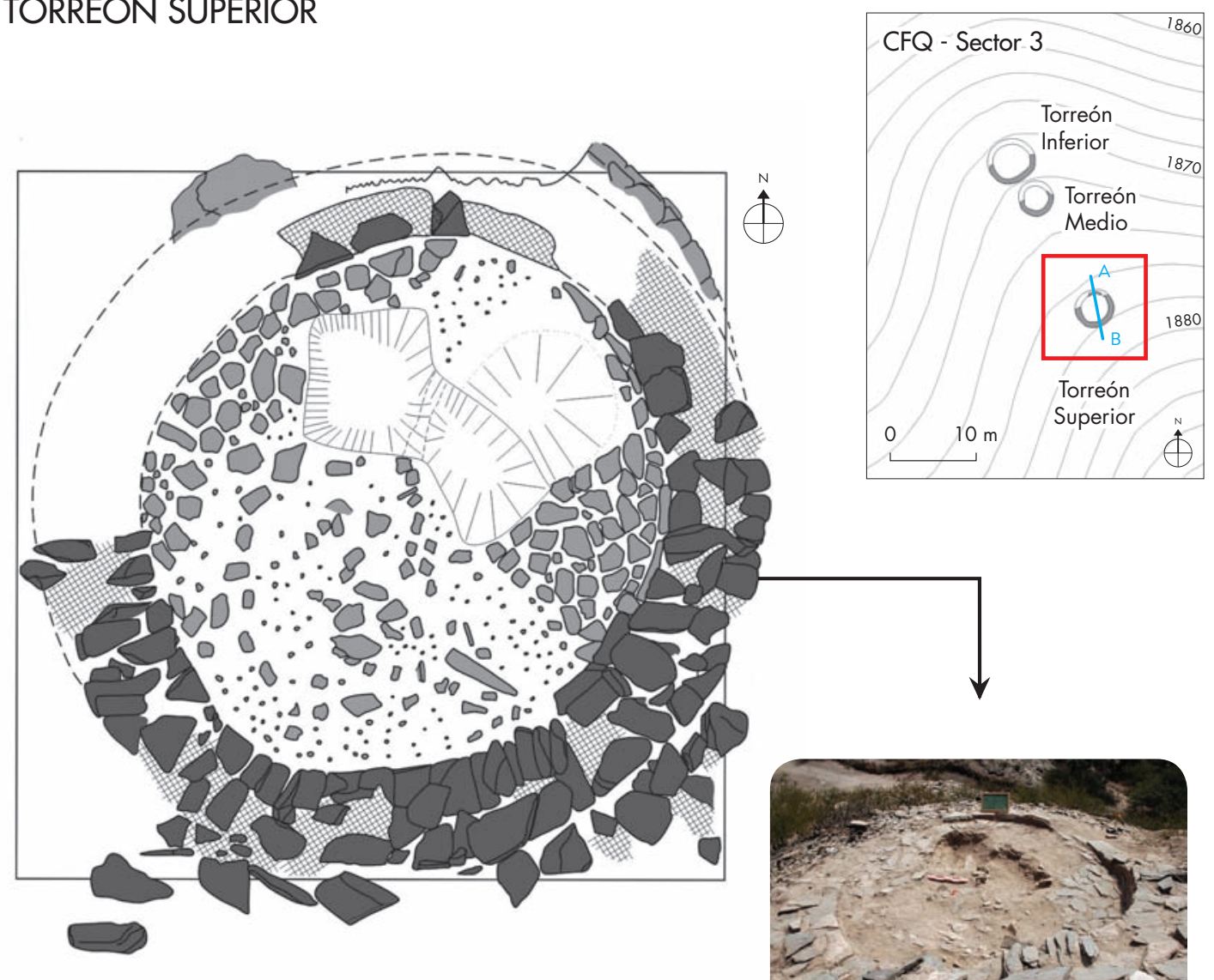

VISTA CORTE LATERAL

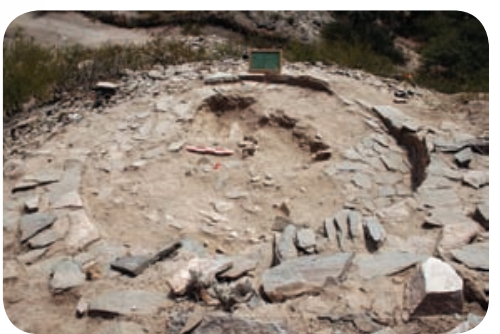

\section{VISTA CORTE LATERAL}

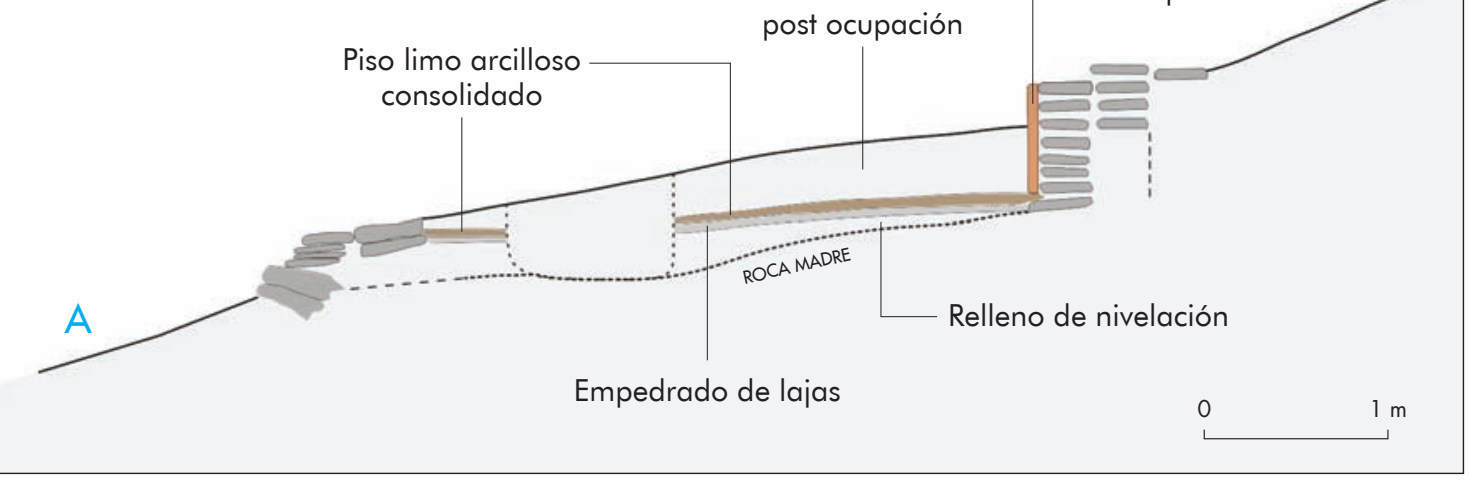

Figura 3. El Calvario de Fuerte Quemado, Torreón Superior (Sector 3). Figure 3. El Calvario de Fuerte Quemado, Torreón Superior (Sector 3). 


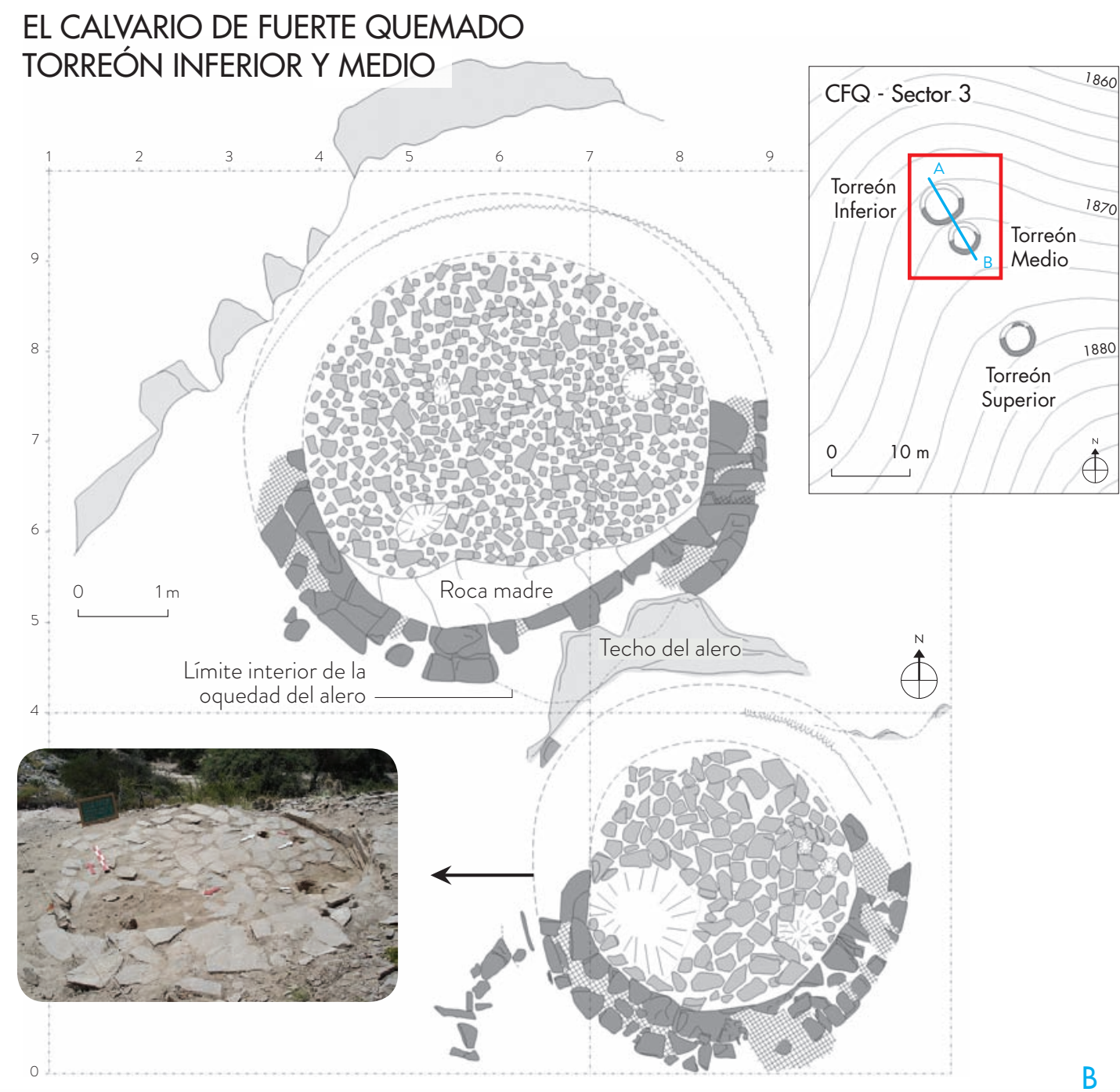

VISTA CORTE LATERAL

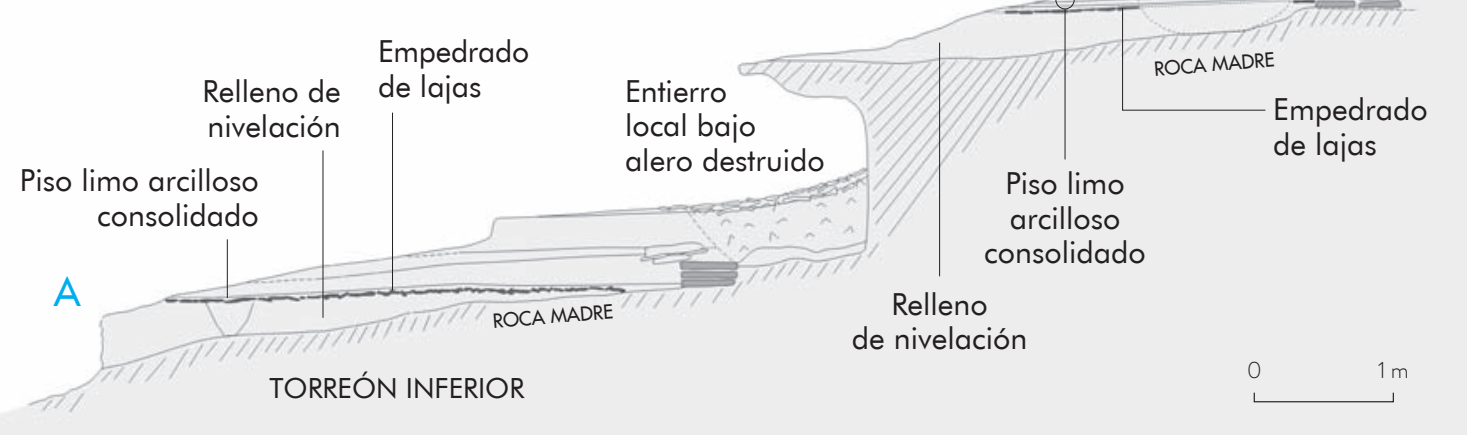

Figura 4. El Calvario de Fuerte Quemado, Torreones Inferior y Medio (Sector 3). Figure 4. El Calvario de Fuerte Quemado, Torreones Inferior and Medio (Sector 3). 
arquitectónica, al concepto de pukara. En las laderas se disponen hileras de recintos de pirca doble, algunos con diseños en zigzag de bloques de cuarzo blanco. Al pie del cerro, por el sur, hemos registrado además otros diez sitios en un área de 31 ha. La planta básica es del tipo cuadrángulo y estructuras anexas (CEA) definido para Rincón Chico, es decir, un gran recinto cuadrangular y estructuras más pequeñas asociadas, rectangulares o circulares. En el sitio Augier (LM1) solo se conservaba un montículo de $30 \mathrm{~m}$ de largo por $20 \mathrm{~m}$ de ancho y algunas líneas de piedras. Se excavaron varias cuadrículas en el eje longitudinal. En el centro del montículo (cuadrícula D3a) se registró un fogón y evidencias pirometalúrgicas y se recuperaron algunos fragmentos Rojo Pulido e Inca Provincial, entre otros estilos tardíos (Palamarczuk \& Greco 2012; Greco 2012, 2014). Una muestra de granos carbonizados de maíz del fogón brindó una datación de 400 \pm 60 AP (LP 1310) (Cal. 2 sigma 1445 (95,4\%) $1641 \mathrm{DC})$. Este sitio se ubica al oeste del camino vecinal Lampacito-Las Mojarras, el que se habría sobreimpuesto al Camino Inca en este sector.

La localidad arqueológica de Rincón Chico abarca una superficie de 500 ha, con construcciones de muros de piedra y argamasa de barro que conforman unidades domésticas, instalaciones de trabajo artesanal, espacios ceremoniales y áreas de tránsito (Tarragó 2011). El pukara (sitio RCh1) cubre 39,6 ha, mientras que el resto de los 36 sitios se disponen sobre un cono de deyección de la Sierra del Cajón. Del conjunto de más de 40 fechados radiocarbónicos, varios de RCh1, y también de RCh12, RCh14 y RCh15 se extienden desde el siglo XIV hasta inicios del XVII, es decir, dentro de la época Inca y Colonial temprana. Particularmente interesante es el contexto de actividades destinadas a la producción de chicha en el sitio RCh14, donde la conservación in situ de los molinos para la molienda y restos de los grandes "virques" podría vincularse con las festividades propiciadas por el Inca que incluían libaciones (Tarragó et al. 1999). Del mismo modo, la escala de producción de bienes ceremoniales de bronce estannífero en el taller metalúrgico de RCh15 se amplió en esos momentos, incorporando una batería de hornos de cuba del tipo huayra, quedando evidencias de moldes de "lingotes" y de discos tardíos (González 2004). Sin embargo, es necesario recalcar que en la mayoría de los sitios solo hemos recuperado vestigios cerámicos de los estilos locales como Santa María Bicolor y Negro sobre Rojo, Famabalasto Negro Grabado y vasijas domésticas con pie de compotera. La excepción fueron escasos fragmentos de alfarería Inca Mixta en RCh12 y RCh13 (Palamarczuk 2002, 2011) (fig. 5).

\section{SHIQUIMIL-AMPAJANGO}

La Loma Rica de Shiquimil es un gran poblado tipo pukara ubicado sobre un cerro testigo que se emplaza en la margen derecha del río Santa María, entre los poblados actuales de Entre Ríos y Andalhuala. Conocido desde el siglo XIX, sufrió diversas intervenciones en búsqueda de bienes funerarios por parte de I. Liberani y J. Hernández, V. Weiser y A. Methfessel. A partir de 1986 iniciamos tareas de prospección y excavación que han permitido estudiar la cerámica de superficie y realizar dataciones. Los cuatro fechados promediados dan la siguiente calibración con 2 sigma: 1420 (87,6\%) 1504; 1590 (7,8\%) 1616 (Greco 2014), es decir, cae en el período tratado, aunque su ocupación debe retrotraerse en varios siglos. ${ }^{2}$ Entre los materiales ilustrados por Liberani y Hernández (1950: lám. 13 y 23; González \& Tarragó 2005: fig. 16) se encuentra un jarro de asa lateral Inca Provincial con decoración pintada en rojo sobre blanco y ollas con pie de compotera.

El sitio Ampajango 2-Rosendo Cáceres cubre una superficie mínima de $11 \mathrm{ha}$. Se emplaza a $2.100 \mathrm{msnm}$, a lo largo de una angosta terraza transversal al valle, entre el río homónimo al sur y un profundo cauce estacional por el norte. El relevamiento permitió delimitar cinco sectores a partir de muros que cortan transversalmente la terraza y que coinciden con desniveles en la pendiente del terreno. De acuerdo a las evidencias arquitectónicas y al material cerámico de superficie, el sitio muestra una prolongada ocupación, por lo menos desde fines del Formativo al Inca y Colonial Temprano (fig. 6).

El Sector IV demuestra una marcada remodelación arquitectónica en la época Inca. Se destaca la plaza central, la cual, siguiendo la topografía, presenta una planta poligonal demarcada por un muro de circunvalación de pirca doble. En su extremo oriental, una rampa de 3,5 $\mathrm{m}$ de ancho, tras descender al cauce estacional, conduce al conjunto denominado Casas Viejas (Ampajango 3) que posee también las características de una kancha incaica. En dirección contraria, una de las escaleras lleva a la playa del río Ampajango, donde comienzan los cuadros de cultivo. Hacia el occidente, el asentamiento estaba custodiado desde la Loma Redonda 


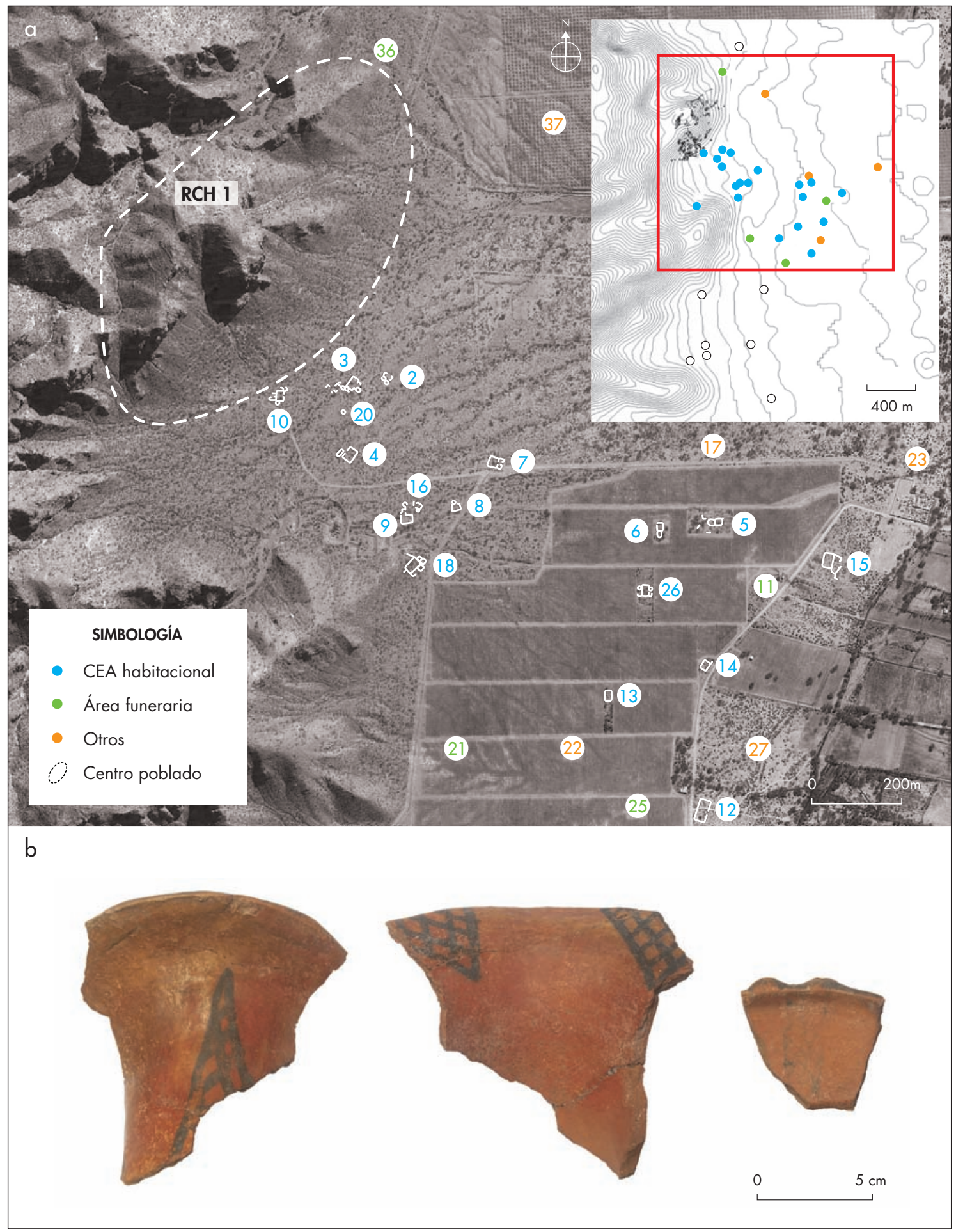

Figura 5: a) vista aérea de Rincón Chico, tomado de Greco (2014: fig. 3, pp. 21). Se destaca el sector del pukara RCh1 y los sitios dispersos en el piedemonte; b) hallazgos de cerámica de estilos incaicos en superficie de RCh13. Figure 5: a) aerial view of Rincón Chico, image by Greco (2014: fig. 3, pp. 21). The area of the pukara RCh1 is highlighted, as the sites spread over the piedmont; $\boldsymbol{b}$ ) superficial findings of Inca style pottery in RCh13. 


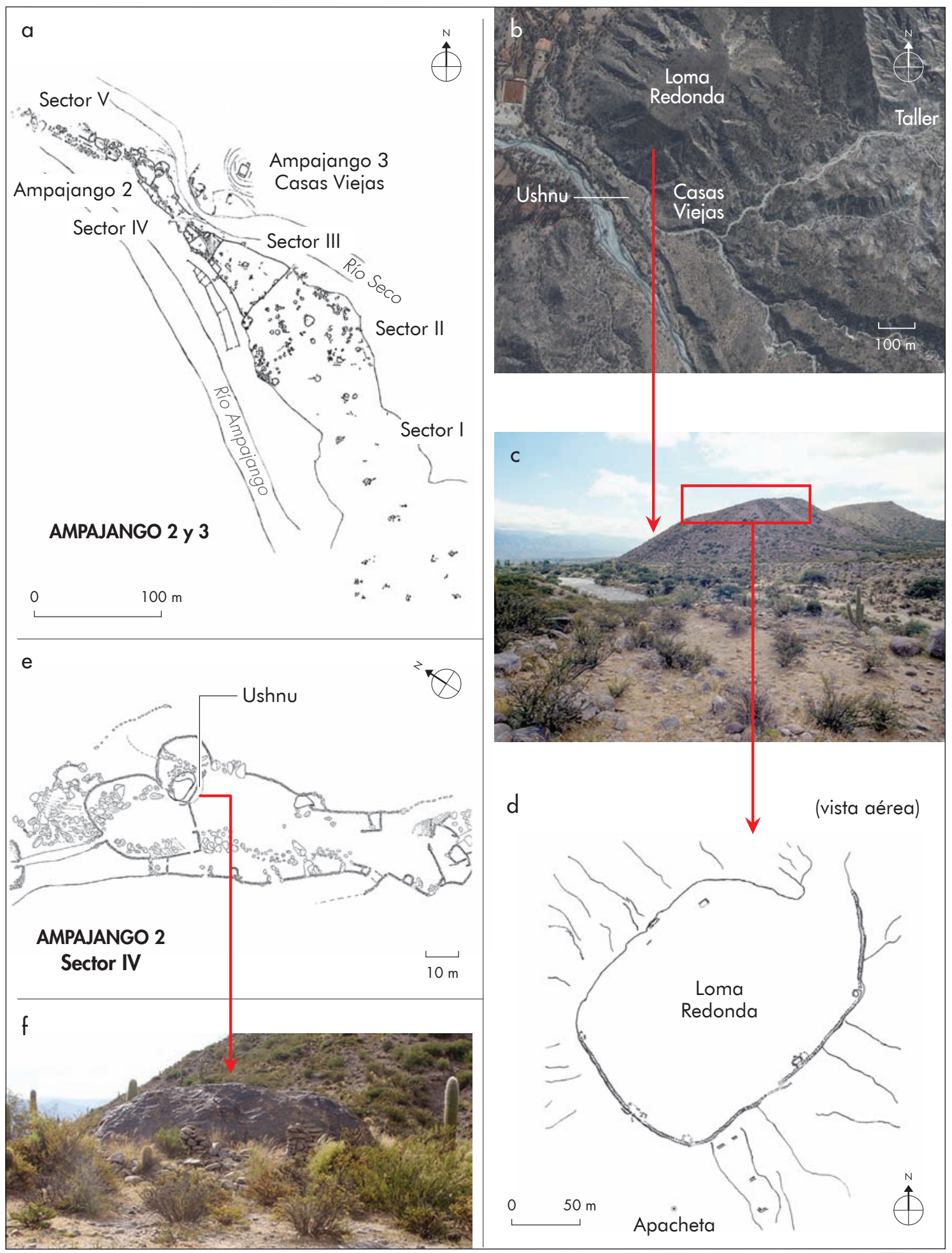

Figura 6. Planimetrías y vistas del sitio Ampajango: a) diferentes sectores de Ampajango 2 y 3; b-d) Loma Redonda (Ampajango 7); e-f) Sector Plaza y Ushnu en Ampajango 2. Figure 6. Charts and views of the Ampajango site: a) different sectors of Ampajango 2 and 3; b-d) Loma Redonda (Ampajango 7); e-f) Plaza area and Ushnu in Ampajango 2. 


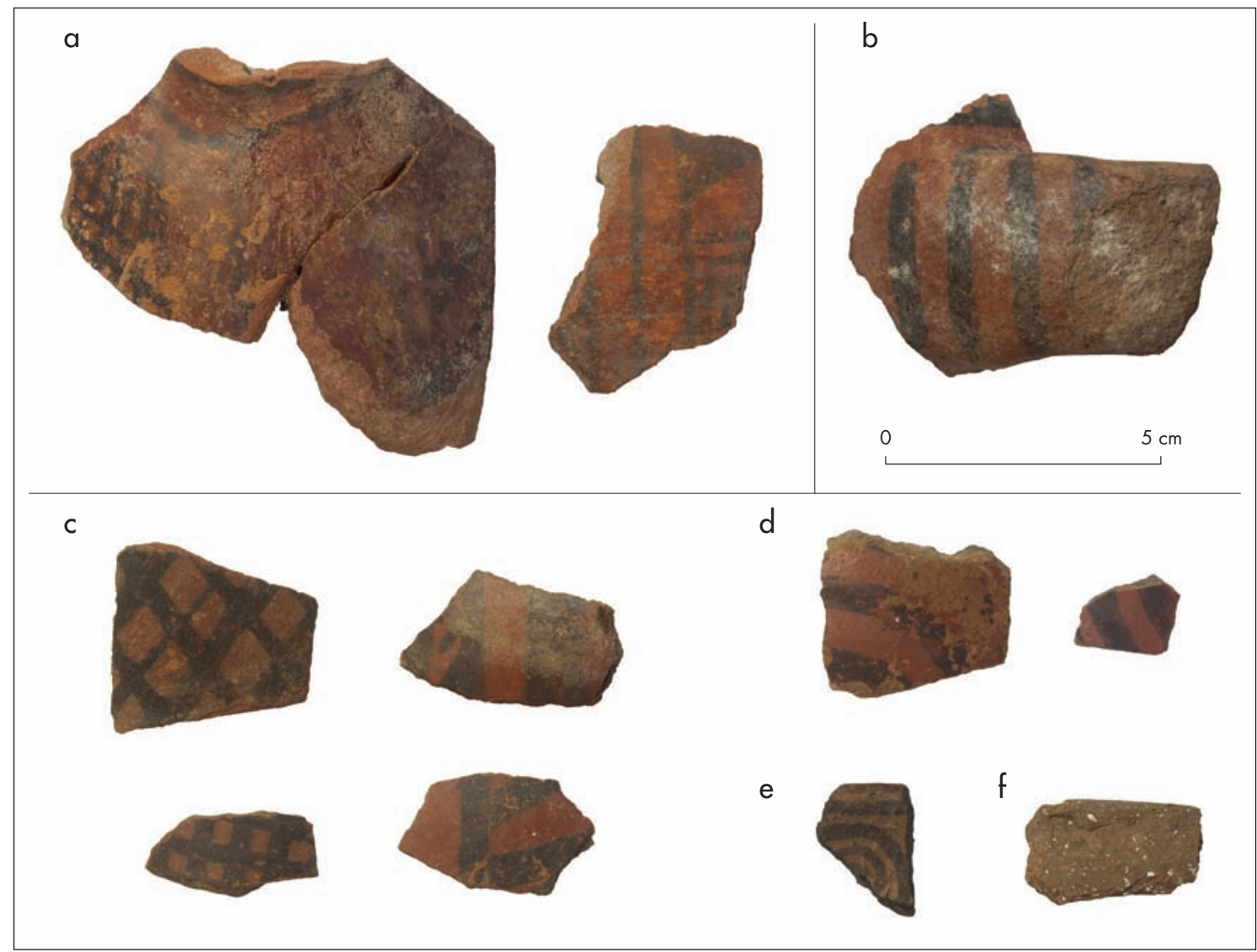

Figura 7. Fragmentos cerámicos de época Inca recuperados en superficie del sitio Ampajango 2: a) Inca Mixto; b) Santa María-Belén; c) estilos locales Negro sobre Rojo; d) Famabalasto Negro sobre Rojo; e) Negro sobre café pulido; f) Ordinario Alisado con muscovita. Figure 7. Ceramic fragments of Inca period recovered on site surface in Ampajango 2: a) Inca Mixed; b) Santa María-Belén; c) Black on Red; d) Famabalasto Black on Red; e) Black on Brown Polished; f) Straightened Ordinary with moscovite.

(Ampajango 7) donde se registró un reducto amurallado de cumbre y muros de contención en ladera (Tarragó \& González 2005).

En la esquina noroeste de la plaza se encuentra una estructura dominada por un enorme peñasco de $10 \mathrm{~m}$ de largo en sentido este-oeste, $4 \mathrm{~m}$ de ancho y $3 \mathrm{~m}$ de altura promedio, que ha sido definido como ushnu (González \& Tarragó 2005: fig. 15). En la cara que mira hacia la plaza y más allá, hacia las cumbres nevadas de la cadena del Aconquija, el peñasco fue enmarcado por dos líneas de plataformas realizadas con rocas de formas regulares, algunas con canteado. Hacia el norte y este, el desnivel del terreno fue compensado con cuatro y cinco líneas de plataformas, habiéndose incluido una rampa que permite ascender a la cúspide plana de la gran roca. Un primer fechado sobre carbón vegetal proporcionó un valor de $340 \pm 130 \mathrm{AP}$ (Beta 146374) (Cal. 2 sigma 1418
(84,8\%) 1818 DC; 1827 (6,5\%) 1894 DC; 1910 (4\%) 1952 DC). La muestra cerámica de superficie y de excavación ofreció tipos Famabalasto Negro sobre Rojo, Santa María Bicolor y Negro sobre Rojo, Quilmes Inciso e Inca (fig. 7). En la superficie de la plaza se recogió un liwi incaico (pequeña bola para cazar pájaros) de bronce estannífero (González \& Palacios 1996; Tarragó \& González 2005).

\section{PUNTA DE BALASTO}

En el confín del valle y a unos $10 \mathrm{~km}$ al sudoeste de Ampajango 2, se levantaba el Tambo de Punta de Balasto, sobre el camino troncal que recorría el fondo del bolsón $\mathrm{y}$ en un punto del paisaje sin ocupaciones previas. El tambo fue interpretado como una estación de control del tránsito de personas y del voluminoso tráfico de bienes 
dentro del conjunto de instalaciones administrativas del sur del Collasuyu (González 1999: 227-228). Por ejemplo, una carta del jesuita Juan de León en 1657 menciona que cada año pasaban por el valle "quatro cientos carneros cargados de oro" como parte de la renta para el Inca (Tarragó \& González 2005: 141-143).

El tambo se emplaza a $2.140 \mathrm{msnm}$ en la margen oriental del río Santa María y ocupa una franja de casi un kilómetro de largo en el fondo de valle, entre el río y la ruta 40 , cubriendo unas 10 ha. Fue identificado por Bruch (1911) y excavado por el equipo de Cigliano (Carrara et al. 1960). Desde 1988, el Proyecto Arqueológico Yocavil realizó prospecciones y excavaciones (González 1999; González et al. 2007). El tambo fue dividido en trece grupos arquitectónicos, que comprenden un ushnu de $5 \times 5 \mathrm{~m}$ asociado a una gran plaza de $80 \times 98$ $\mathrm{m}$, dos conjuntos de estructuras y muros vinculados al complejo plaza-ushnu (Grupo 6), tres kanchas de $30 \mathrm{~m}$ de largo (Grupos 7, 8, 12), una estructura rectangular alargada sin subdivisiones internas de $33 \times 10 \mathrm{~m}$ tipo kallanca (Grupo 9), estructuras vinculadas a una plaza de $70 \times 35 \mathrm{~m}$, collcas circulares (Grupo 11) y rectangulares (Grupo 2), unidades residenciales (Grupo 1) y un conjunto de estructuras que pudieron formar parte de otras kanchas (fig. 8).

El diseño arquitectónico dual y la presencia del complejo plaza-ushnu, de kanchas y collcas indican que es un sitio de planificación netamente estatal. El camino que divide al sitio en mitades, sin mojones, fue un eje estructurador de la arquitectura, como evidencia la construcción de edificios orientados según su dirección. Su traza puede apreciarse con claridad debido a su ancho regular que varía de 3 a 3,70 $\mathrm{m}$ y a las modificaciones del sustrato producidas a través del tránsito, elementos que lo hacen visible no solo en el terreno sino también en las imágenes satelitales y en las fotografías aéreas de ese tramo. La planta característica de las estructuras es rectangular. La técnica constructiva es la de muro doble sin relleno de $70 \mathrm{~cm}$ de ancho, formado por dos líneas paralelas de bloques redondeados unidos con mortero de barro o mediante pirca seca, diferente del muro doble con relleno de tierra y ripio característico de los poblados locales tardíos. Algunas piedras están canteadas y otras cuidadosamente seleccionadas (González 1999).

Hasta ahora se han realizado recolecciones de superficie en todos los sectores y excavaciones en los Grupos 7, 9, 10 y 12. El material más abundante en el sitio es la alfarería. El conjunto cerámico de superficie y excavación ( $\mathrm{n}=1264)$ está formado por cerámica Inca (42\%), Famabalasto Negro sobre Rojo (7\%), Santa María Bicolor (3\%), Ordinaria que incluye ollas con pie de compotera (29\%) y de otros tipos e inclasificada (19\%) (Marchegiani 2012). El estilo Inca Provincial es el más representativo del sitio, mientras que la frecuencia de los estilos Santa María Bicolor, Inca Paya, La Paya Dibujos Negros, Yocavil Polícromo y Santa María-Belén Negro sobre Rojo es muy baja (fig. 9).

En los sondeos del Grupo 7 se identificó un área de cocción de alimentos, consumo y descarte donde se halló cerámica Ordinaria Alisada, Inca Provincial, Inca indeterminada y Famabalasto Negro sobre Rojo, así como restos óseos quemados asociados a lentes de ceniza y concentraciones carbonosas de las que se obtuvo una muestra de carbón vegetal fechada en $680 \pm 70$ (LP816) (Cal 2 sigma 1235 (0,8\%) 1243 DC; 1265 (94,6\%) 1429 DC). Sobre el piso de un recinto del Grupo 12 se halló cerámica Inca Provincial y Ordinaria, asociada a un cincel de bronce, un núcleo bipolar de obsidiana y un pequeño instrumento de hueso. En la superficie de distintos grupos arquitectónicos se recuperaron, entre otros hallazgos, cuatro puntas de proyectil triangulares de base escotada, dos silbatos de cerámica y un tortero gris de cerámica inciso con motivos geométricos (fig. 10).

La cerámica y los materiales asociados indican que en el tambo se realizaron actividades de preparación, transporte, almacenaje y consumo de alimentos. La presencia de torteros y otros instrumentos, por su parte, permite suponer que también se desarrollaron actividades vinculadas con la producción artesanal. La cerámica Inca Provincial, Famabalasto Negro sobre Rojo, Santa María Bicolor y Ordinaria Alisada está presente en todos los sectores. La kallanca es el grupo con mayor frecuencia de alfarería Inca Provincial y mayor diversidad de estilos cerámicos; de allí proceden un fragmento de plato Inca Provincial de posible origen altiplánico (fig. 9 a) y también fragmentos de ollas con pie de compotera. También se observó que la mayor frecuencia de cerámica Famabalasto Negro sobre Rojo, al igual que el hallazgo de los fragmentos Yocavil Polícromo y los torteros con decoración geométrica incisa, elementos todos vinculados con la región chaco-santiagueña, provienen de grupos arquitectónicos situados al oriente del camino. Sin embargo, las evidencias disponibles hasta el momento son insuficientes para realizar inferencias sobre sus implicancias en términos de relaciones intergrupales dentro del tambo. 


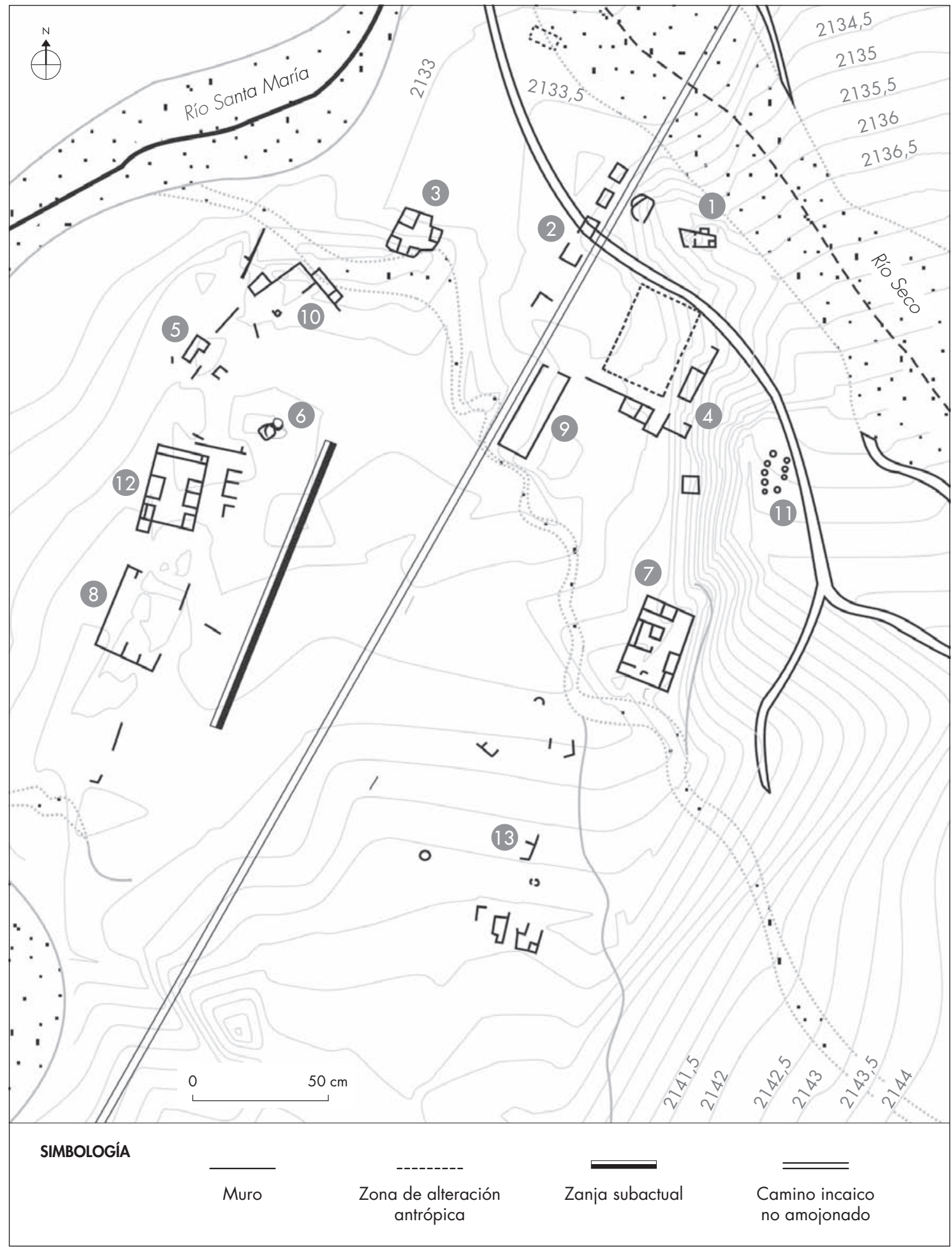

Figura 8. Plano del Tambo de Punta de Balasto, modificado de González (1999). Grupo 6: ushnu-plaza; Grupos 7-8-12: kanchas; Grupo 9: kallanca; Grupo 11: collcas. Figure 8. Map of the Tambo of Punta de Balasto, modified by González (1999). Group 6: ushnu-plaza; Groups 7-8-12: kanchas; Group 9: kallanca; Group 11: collcas. 


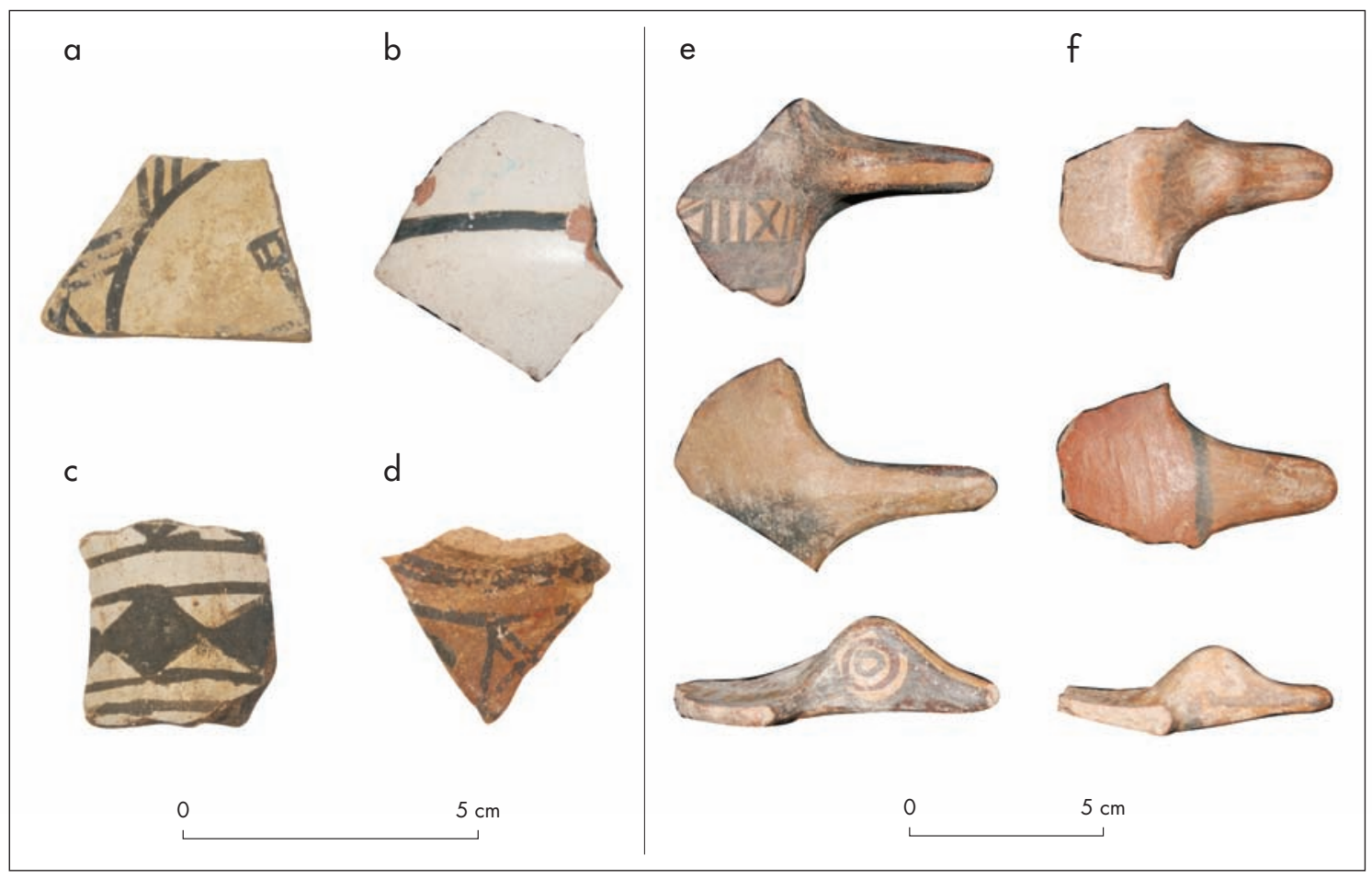

Figura 9. Cerámica Inca del Tambo de Punta de Balasto: a-e) fragmentos estilo Inca Provincial; f) plato pato Inca Paya. Figure 9. Inca pottery from the Tambo of Punta de Balasto: a-e) fragments, Inca Provincial style; f) Inca Paya duck-style plate.

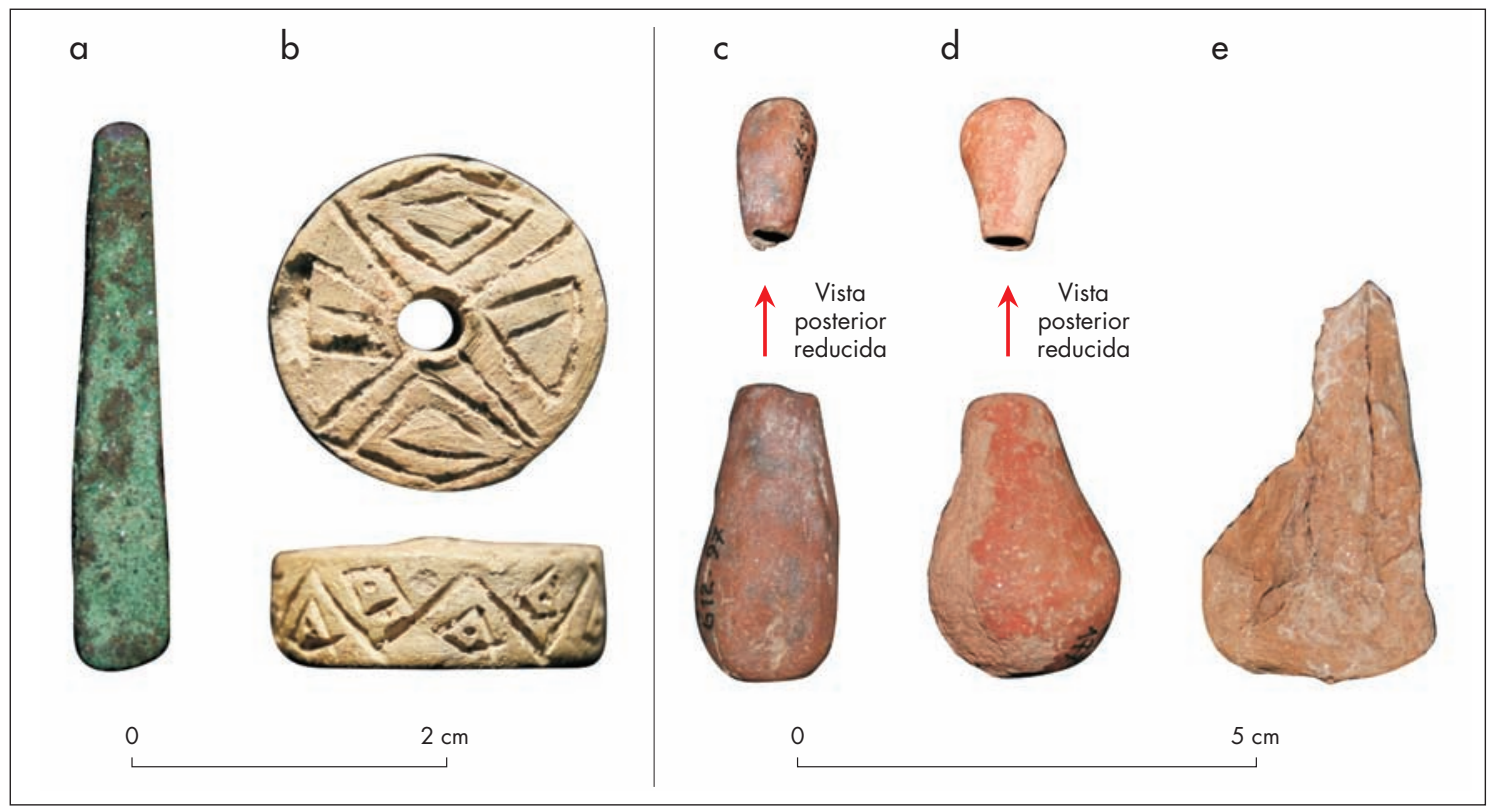

Figura 10. Objetos hallados en el Tambo de Punta de Balasto: a) cincel de bronce (Grupo 12); b) tortero de cerámica inciso con motivos geométricos (Grupo 4, superficie). Silbatos de cerámica: c) Grupo 12; d-e) Grupo 9. Figure 10. Artifacts found in the Tambo of Punta de Balasto: a) bronze chisel (Group 12); b) ceramic spindle weight with geometric patterns (Group 4, surface). Whistles of ceramic material: c) Group 12; d-e) Group 9. 
Asociado a Punta de Balasto se encuentra Bicho Muerto, representando la ocupación parcial de una población preexistente. Es posible que en el primer momento de la expansión incaica Bicho Muerto hubiera actuado como una fortaleza interna, función que más tarde, con la ocupación consolidada, habría sido más simbólica que efectiva. La información etnohistórica indica que el Morro Blanco, a cuyo pie se levanta el asentamiento, constituía una venerada huaca en tiempos prehispánicos tardíos (Piossek Prebisch 1984). Su potencial simbólico habría sido incrementado por los depósitos minerales que albergaba la formación y que abastecían a los cercanos establecimientos metalúrgicos coloniales de El Trapiche y Fundición Navarro (González 1997). Es posible, entonces, que algún sector de Bicho Muerto constituyera un "mochadero minero", en una situación similar a las registradas en otros lugares surandinos, como en KonaKona, en la subregión del alto Loa (Castro 1992).

En la margen occidental y custodiando el tambo se yergue el Cerro Mendocino con su excelente pukara de la cima y laderas. Por su difícil acceso y la presencia de construcciones defensivas, se suele considerar al asentamiento una "fortaleza", arquitectónicamente una de las más destacadas del NOA. Al menos parte de esta instalación seguía en funcionamiento en la época inca, a juzgar por el Grupo A de edificios levantado con bloques canteados de cuarcita borra-vino (Carrara et al. 1960: 37) y la gran kancha al pie (González \& Tarragó 2005: 80-83).

\section{LA VARIABILIDAD ALFARERA DURANTE LA DOMINACIÓN INCA}

Las distintas variantes de la cerámica Inca presentan una distribución diferencial, según se trate de instalaciones de planificación estatal, asentamientos locales con sectores incaicos o poblados sin evidencias arquitectónicas inca. Por otro lado, el proceso de dominación incaica trajo aparejados cambios en los estilos cerámicos preexistentes y generó el surgimiento de estilos nuevos.

El Tambo de Punta de Balasto se destaca por el hallazgo de tiestos Inca Provincial. Los estudios cerámicos que integraron análisis macroscópicos y petrográficos permitieron identificar dos modalidades mayoritarias en la producción de pastas de la cerámica Inca del tambo. La primera y más frecuente se caracteriza por la presencia de inclusiones de muscovita, predominando las de tamaño grande y muy grande, $\mathrm{y}$ aunque a nivel macroscópico el elemento que más se destaca es la mica, el cuarzo es el tipo de inclusión más abundante. La segunda se caracteriza por la adición intencional de inclusiones de ceniza volcánica. Además de cerámica Inca, las pastas con muscovita se utilizaron para elaborar cerámica Ordinaria Alisada, incluyendo ollas con pie de compotera. Aún no contamos con datos sobre el lugar de producción de estas dos modalidades, pero sí podemos afirmar que difieren de las tecnologías de producción originarias del estilo Santa María de Yocavil, caracterizado por la incorporación intencional de tiesto molido como antiplástico. En menor proporción, también se registró cerámica Inca Provincial elaborada mediante otras tecnologías (Marchegiani 2012). Las formas más frecuentes son las botellas (aríbalos, aribaloides y botellas con asa lateral), jarros con asa lateral y platos, todas ellas vinculadas a las actividades de servir y consumir alimentos; por lo tanto, se trata de formas que desempeñaron roles importantes en las estrategias políticas imperiales que incluían situaciones de comensalidad. Los fragmentos Inca Provincial aparecen asociados a cerámica Inca monocroma pulida (principalmente roja y ante), Inca indeterminada, Famabalasto Negro sobre Rojo y Yocavil Polícromo, cerámica local Santa María Bicolor y, excepcionalmente, fragmentos de estilos Inca mixtos como Inca Paya y La Paya Dibujos Negros (figs. 11 y 12).

En los sitios locales con sectores incaicos, como El Calvario de Fuerte Quemado, se registraron fragmentos de cerámica Inca Provincial. Otra situación se comprueba en otros centros poblados locales, como por ejemplo Rincón Chico, para el cual existe constancia de la perduración de su ocupación en momentos incaicos. Allí, luego de intensos trabajos de campo que involucraron todos los sectores del asentamiento, entre miles de fragmentos cerámicos recuperados no se han hallado aún fragmentos Inca Provincial. Estas "ausencias" son también reveladoras: la circulación en el espacio regional de los estilos Inca Provincial, tan connotados simbólicamente, fue dispar y acotada a determinadas localidades, en comparación con la importancia regional y amplia incidencia macrorregional de los estilos de época Santa María y Famabalasto Negro Grabado.

Por su parte, las variantes de cerámica Inca mixta, que integran rasgos locales e incaicos, están presentes en todos los sitios presentados en este trabajo. Cabe señalar 


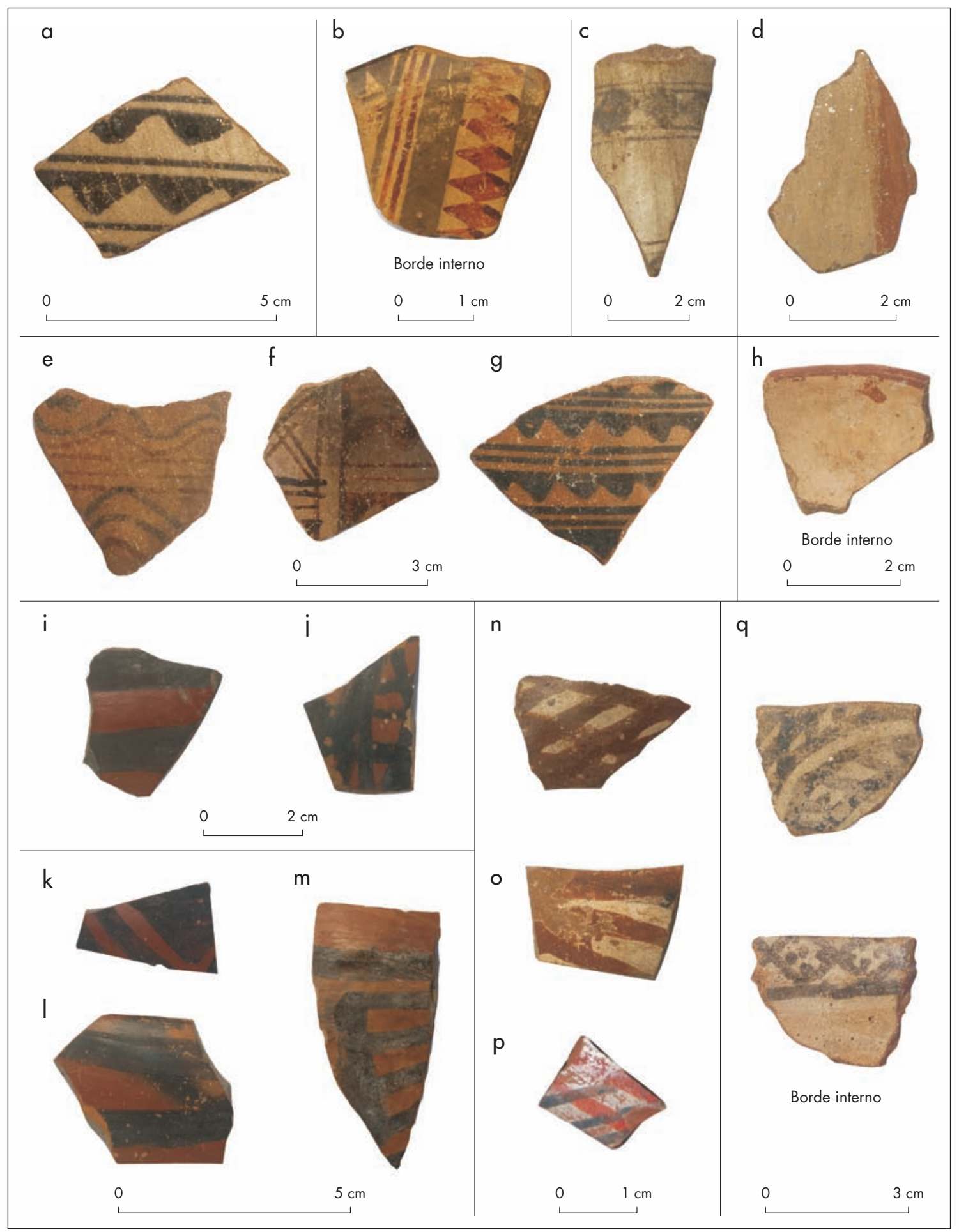

Figura 11. Fragmentos cerámicos recuperados en el Tambo de Punta de Balasto: a-d) Inca Provincial; e) Inca indeterminado; f-h) Inca Provincial; i-m) Famabalasto Negro sobre Rojo; n-p) Yocavil Polícromo; q) Santa María Bicolor. Figure 11. Pottery fragments recovered in the Tambo of Punta de Balasto: $\boldsymbol{a}$-d) Inca Provincial; $\boldsymbol{e}$ ) indetermined Inca; $\boldsymbol{f}$ - $\boldsymbol{h}$ ) Inca Provincial; $\boldsymbol{i}-\boldsymbol{m}$ ) Famabalasto Black on Red; $\boldsymbol{n}$ - $\boldsymbol{p}$ ) Yocavil Polychrome; q) Santa María Bicolor. 


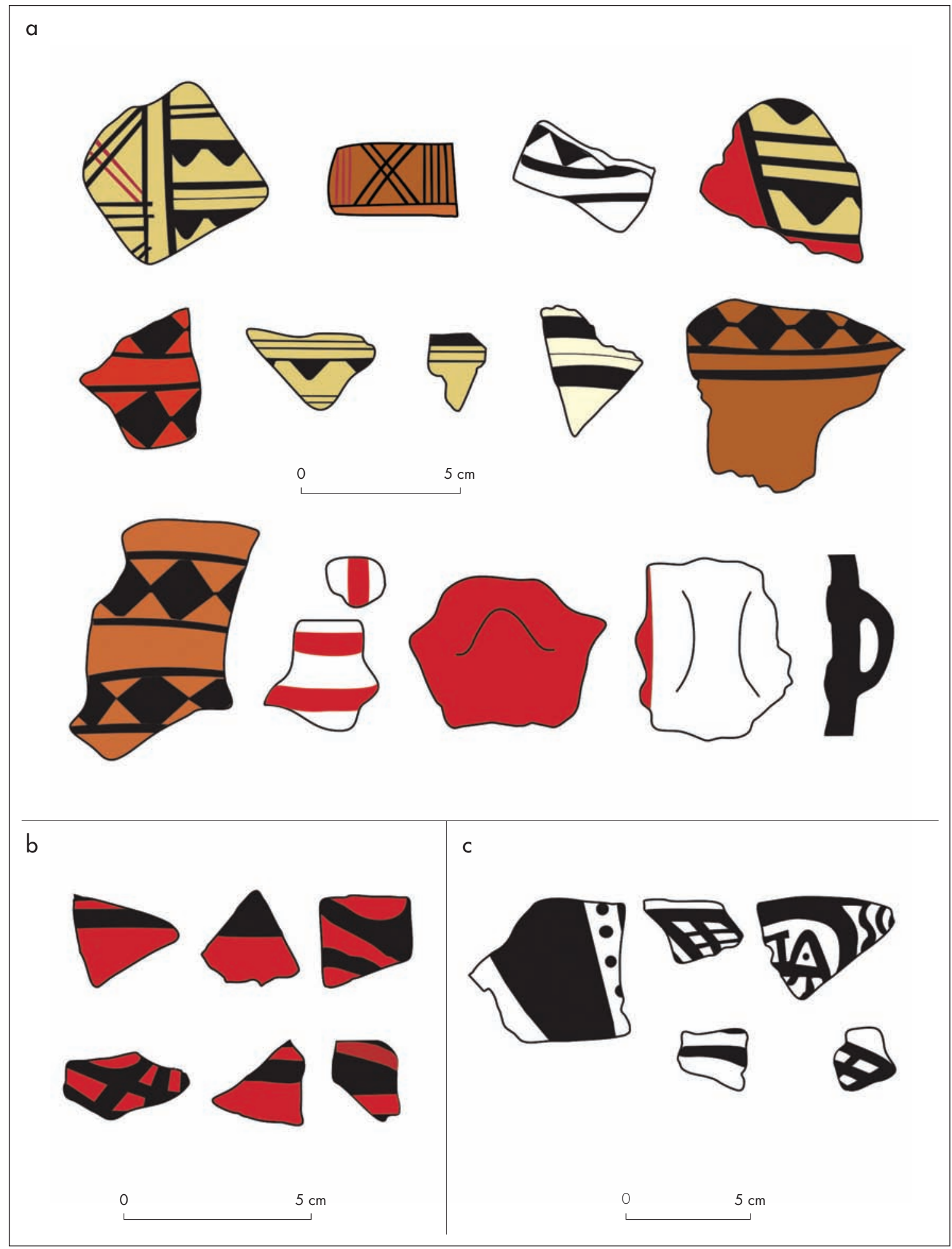

Figura 12. Fragmentos cerámicos recuperados en el Tambo de Punta de Balasto: a) Inca Provincial; b) Famabalasto Negro sobre Rojo; c) Santa María Bicolor. Figure 12. Pottery fragments recovered in the Tambo of Punta de Balasto: $\boldsymbol{a}$ ) Inca Provincial; $\boldsymbol{b}$ ) Famabalasto Black on Red; c) Santa María Bicolor. 
que a partir del estudio de colecciones de museos ${ }^{3}$ y de materiales publicados, el área de Fuerte Quemado se destaca también como localidad de marcada circulación de cerámica incaica en sus distintas variantes (fig. 13).

Un elemento fundamental del desarrollo alfarero en Yocavil en la época Inca es la perduración del estilo Santamariano, aunque esta continuidad se produjo en el marco de ciertas innovaciones en la forma -aparición de pucos con punto angular y alargamiento de cuellos en las urnas- y en la iconografía -motivos geométricos con relleno reticulado, guardas horizontales de triángulos plenos negros, figuración de "guerreros" y escutiformes, felinización de motivos zoomorfos como el suri y el camélido (Reynoso \& Pratolongo 2008; Marchegiani et al. 2009)-. A su vez, surgieron nuevas modalidades estilísticas, como las urnas Negro sobre Rojo que integran rasgos Santa María y Belén. Simultáneamente, en esta época se introdujeron en el valle diversos estilos originarios de otras regiones, como las vasijas y cuencos Famabalasto Negro sobre Rojo y Yocavil Polícromo de Santiago del Estero, y los pucos Yavi de la puna jujeña (Marchegiani et al. 2009). Si bien su presencia es minoritaria, resultan buenos indicadores cronológicos, debido a que su producción y distribución estuvo mediada en cierto grado por la agencia incaica (fig. 14).

Al situarnos desde la perspectiva de los grupos dominados, podemos dar cuenta de que la presencia de estos estilos mixtos y no incaicos (locales y no locales) otorga visibilidad al proceso de expansión incaica en Yocavil, incluso en espacios con ausencia de bienes muebles netamente incaicos. Las estrategias políticas incaicas incluirían el aprovechamiento del prestigio regional de determinados bienes apropiándose de los mecanismos de su distribución social, lo que puede resultar coherente con la amplia representación de los materiales santamarianos (González \& Tarragó 2004). Por su parte, esta perduración en la producción de determinados bienes indica, además de sus atributos de calidad, ciertos niveles de autonomía organizativa en su producción y en la reproducción de sistemas de representaciones por parte de los grupos locales. La comprensión del proceso de dominación incaica en regiones consideradas marginales, como los Andes meridionales, requiere una perspectiva amplia capaz de integrar la diversidad de evidencias de esa expansión, evidencias que muchas veces pueden ser sutiles o pasar desapercibidas si solo observamos desde la perspectiva de los lugares centrales.

\section{DISCUSIÓN Y CONCLUSIONES}

A los sitios aquí desarrollados se suman evidencias de bienes muebles en Caspinchango, la Terraza de Andalhuala Banda, Loma Redonda, Loma Alta y Pajanguillo, entre otros (González \& Tarragó 2005). Los datos construidos a lo largo de casi treinta años de trabajos en la región ponen de manifiesto que la ocupación cuzqueña no siempre se ajustó a criterios "monumentales" (González Godoy 1996: 34) y que el registro arqueológico imperial puede quedar empañado en contextos con preponderancia de elementos locales (Morris 1988: 243-244).

Sobre el particular, hemos propuesto que, en el sur del valle, la dominación incaica, sin dejar de ser intensa, implicó un complejo proceso en el que participaron los intereses del gobierno central y los de los grupos de poder locales; los mecanismos diseñados para alcanzar los objetivos del Estado y las cualidades de la organización social, política y económica de estos grupos locales en la región y la resolución de los conflictos de facciones derivados de las nuevas condiciones (González \& Tarragó 2004; Reynoso 2009).

Considerando la producción tecnológica como un campo adecuado para explorar las formas y resultados del enfrentamiento entre los intereses estatales y los de los sectores subordinados, se han propuesto los cambios y continuidades en la metalurgia y alfarería santamarianas tanto en sus aspectos técnicos como expresivos. De dicho análisis se desprende que, así como la circulación de materiales asociados al imperio operó por canales restringidos, el "modo de hacer" tradicional, en términos amplios, mantuvo vigencia.

Interpretando la evidencia en el marco de fenómenos de resistencia cultural, se propone que los administradores estatales, para alcanzar los objetivos programados para la región, debieron respetar determinados elementos del sistema de representaciones autóctono, a su vez vinculados con cualidades organizativas de las formaciones sociales (González \& Tarragó 2004).

De la misma manera ocurrió en los modos de construir los espacios habitados que, en gran medida, conservaron los patrones locales altamente desarrollados a nivel regional. No obstante, como se refirió en el caso de El Calvario de Fuerte Quemado, el ejercicio de la violencia estatal fue también una estrategia puesta en práctica en el proceso expansivo. Las restricciones observadas en la circulación de bienes netamente incaicos alertan acerca del problema metodológico implícito 


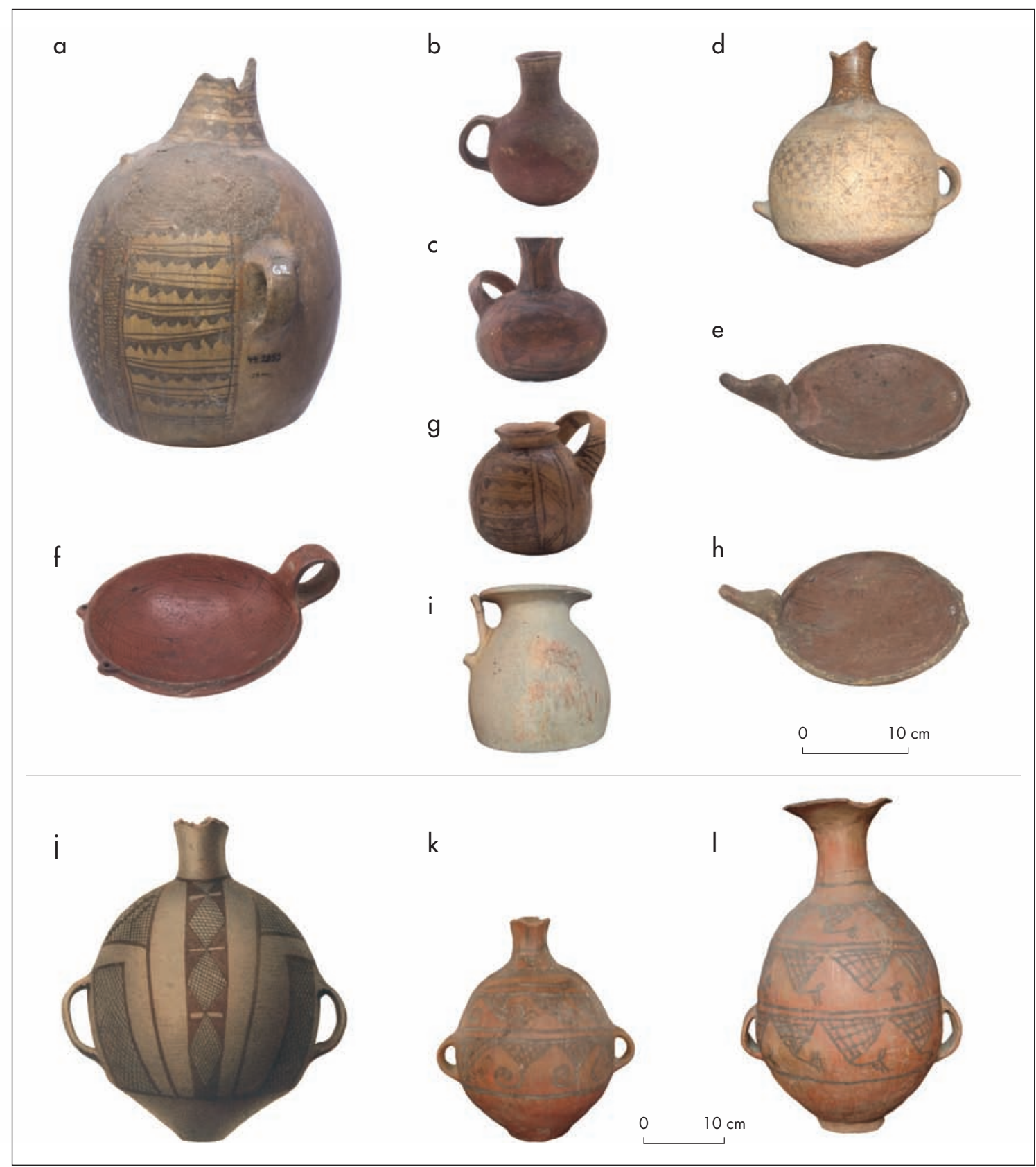

Figura 13. Cerámica de estilos incaicos. Ejemplares de estilos Inca Provincial e Inca mixto procedentes de Yocavil: a) -28000-, Inca Provincial, El Paso, MEjBA; b) -28015-, Inca Provincial, Fuerte Quemado, MEJBA; c) -29107-, Inca mixto, El Paso, MEJBA; d) MLP-Ar-(n)5005, Inca Provincial, Ampajango, MLP; e) -28010-, Inca Provincial, Fuerte Quemado, MEJBA; f) -29073-, Inca Provincial, Amaicha, MEJBA; g) -29108-, Inca Provincial, El Paso, MEJBA; h) -28011-, Inca Provincial, Fuerte Quemado, MEJBA; i) MLP-Ar-(n)4492, Ampajango, MLP; j) 922, Diaguita-Inca, Santa María, Col. MLP (Outes 1907, Plancha III, Nº 6); k) La Paya dibujos negros, Fuerte Quemado La Ventanita, MEB; l) MLP-Ar-(n)4447, La Paya dibujos negros, Masao, MLP. Figure 13. Inca styles pottery. Examples of the Inca Provincial and mixed Inca styles from Yocavil: a) -28000-, Inca Provincial, El Paso, MEJBA; b) -28015-, Inca Provincial, Fuerte Quemado, MEJBA; c) -29107-, Inca Mixed, El Paso, MEJBA; d) MLP-Ar-(n)5005, Inca Provincial, Ampajango, MLP; e) -28010-, Inca Provincial, Fuerte Quemado, MEJBA; f) -29073-, Inca Provincial, Amaicha, мEJвA; g) -29108-, Inca Provincial, El Paso, MEJBA; h) -28011-, Inca Provincial, Fuerte Quemado, MEJBA; i) MLP-Ar-(n)4492, Ampajango, MLP; j) 922, Diaguita-Inca, Santa María, Col. MLP (Outes 1907, Plancha III, $N^{\circ}$ 6); $k$ ) La Paya black drawings, Fuerte Quemado La Ventanita, MEB; l) MLP-Ar-(n)4447, La Paya black drawings, Masao, MLP. 


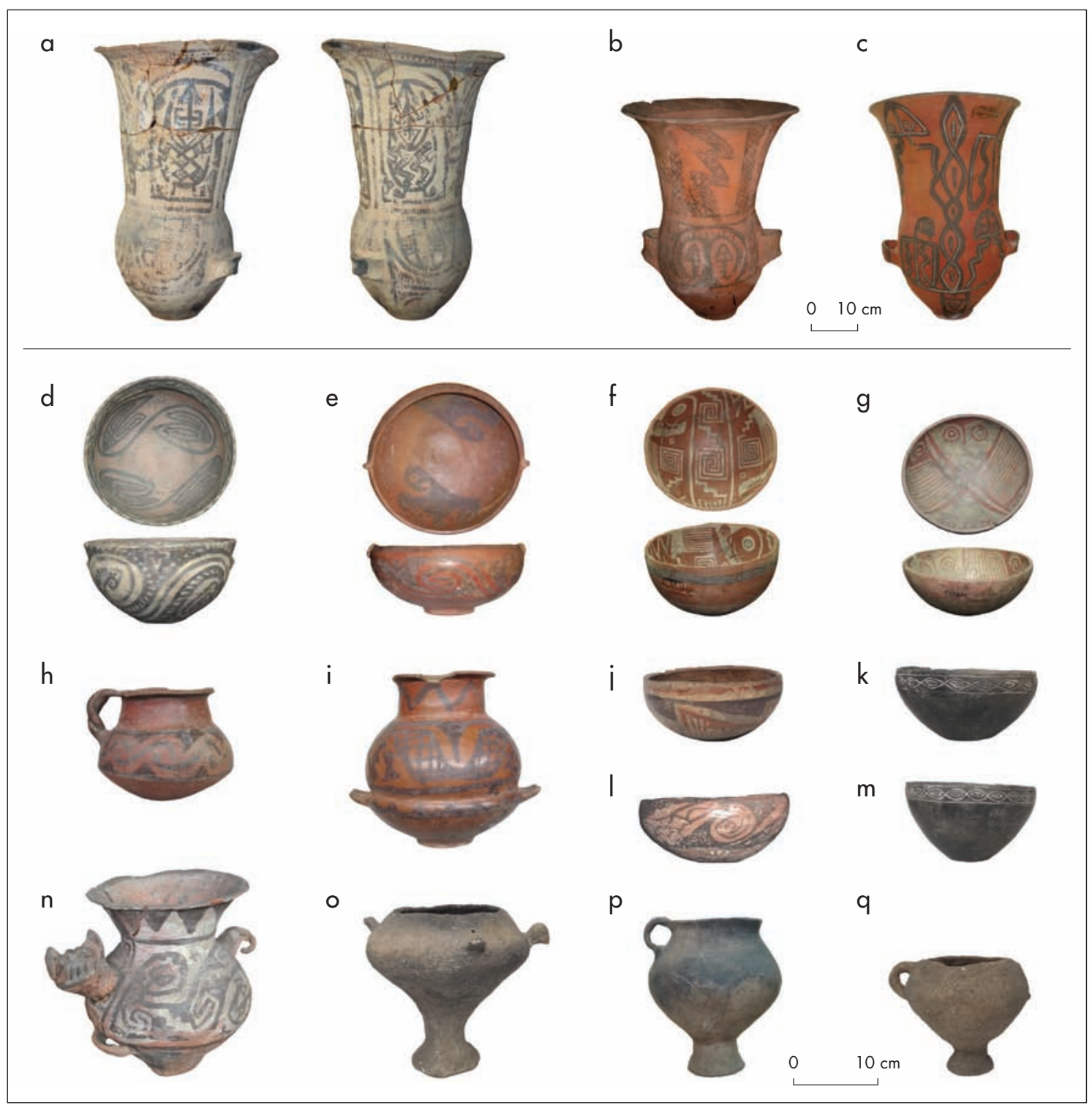

Figura 14. Cerámica local. Diversos estilos alfareros locales correspondientes a la época de expansión incaica: a) MLP-Ar-(n)5695, Santa María Bicolor fase IV, Quebrada Chiquimil, MLP; b) MLP-Ar-(n)4436, Santa María-Belén, Masao, MLP; c) 46-70, Quilmes Inciso, MAC; d) MLP-Ar-(n)5245, Santa María Bicolor, Famabalasto, MLP; e) MLP-Ar-(n)5320, Famabalasto Negro sobre Rojo, Famabalasto, MLP; f) 43-2819, Yocavil Polícromo, Andalhuala, MAC; g) 47-1830, Yocavil Polícromo, Tafí, MejBA; h) MLP -Ar-(n)5335, Famabalasto Negro sobre Rojo, Famabalasto, MLP; i) MLP-Ar-(n)5347, Famabalasto Negro sobre Rojo, Famabalasto, MLP; j) -36966-, Yocavil Polícromo, Quilmes, MEJBA; k) MLP-Ar-(n)5967, Famabalasto Negro Grabado, Lorohuasi, MLP; l) -28040-, Yavi, Amaicha, MEJBA; m) MLP-Ar-(n)5370, Famabalasto Negro Grabado, Famabalasto, MLP; n) MLP-Ar-(n)5266, Santa María Bicolor, Famabalasto, MLP; o) -28012-, Ordinario Alisado, Fuerte Quemado, mejBa; p) 323 Exp. C. Bruch, Ordinario Alisado, Fuerte Quemado, MEaUnR; q) -28013-, Ordinario Alisado, Fuerte Quemado, MEJBA. Figure 14. Local pottery. Several local pottery styles, Inca expansion period: a) MLP-Ar-(n)5695, Santa María Bicolor phase IV, Quebrada Chiquimil; b) MLP-Ar-(n)4436, Santa María-Belén, Masao, MLP; c) 46-70, Quilmes Incised, MAC; d) MLP-Ar-(n)5245, Santa María Bicolor, Famabalasto, MLP; e) MLP-Ar-(n)5320, Famabalasto Black on Red, Famabalasto, MLP; f) 43-2819, Yocavil Polychrome, Andalhuala, MAC; $g$ ) 47-1830, Yocavil Polychrome, Tafí, MEJBA; h) MLP -Ar-(n)5335, Famabalasto Black on Red, Famabalasto, MLP; i) MLPAr-(n)5347, Famabalasto Black on Red, Famabalasto, MLP; j) -36966-, Yocavil Polícromo, Quilmes, MEJBA; $k$ ) MLP-Ar-(n)5967, Famabalasto Black Incised, Lorohuasi, MLP; l) -28040-, Yavi, Amaicha, MEJBA; m) MLP-Ar-(n)5370, Famabalasto Black Incised, Famabalasto, MLP; n) MLP-Ar-(n)5266, Santa María Bicolor, Famabalasto, MLP;o) -28012-, Straightened Ordinary, Fuerte Quemado, MEJBA; p) 323 Exp. C. Bruch, Straightened Ordinary, Fuerte Quemado, MEAUNR; q) -28013-, Straightened Ordinary, Fuerte Quemado, MEJBA. 
en la inferencia del abandono de sitios o traslado de poblaciones a partir de la ausencia de materiales muebles o arquitectura incaica en los poblados locales. Una posibilidad que, no obstante, no puede dejar de considerarse a priori.

Las áreas vinculadas con las actividades ceremoniales y religiosas, como las plazas y ushnu en El Calvario de Fuerte Quemado y en Ampajango 2 fueron, probablemente, los monumentos más versátiles para crear y reproducir las estructuras de poder social. Por un lado, conformaban lugares de convergencia en los cuales las condiciones de desigualdad podían enmascararse a partir de su apariencia pública. Por otro lado, los fundamentos del orden impuesto podían ser renovados y potenciados mediante la intervención de fuerzas sobrehumanas, las que, a su vez, eran presentadas como legitimadoras de la estructura de dominación vigente.

En suma, el caso estudiado pone de manifiesto que la ocupación inca en el sur del valle de Yocavil fue mucho más intensa que lo que conocíamos hace unas pocas décadas, pero con un reflejo arqueológico que no se ajusta estrictamente a los rasgos "típicos" a partir de los cuales suele evaluarse la presencia imperial en los Andes meridionales. Las cualidades de este registro arqueológico señalarían, por una parte, la estrategia de la ocupación imperial en la región, destacando las áreas con un valor particular para los objetivos políticoeconómicos centrales y que, en consecuencia, se juzgaron como adecuadas para ser desarrolladas mediante la inversión en infraestructura. El emplazamiento cercano al camino es un elemento en común a todas ellas y fue estratégico para el control del territorio y de la circulación de bienes y personas.

Sin embargo, de igual modo estas cualidades estarían dando cuenta de las condiciones sociopolíticas y organizativas vigentes, las cuales en algunos casos podrían haber sido funcionales a la administración cusqueña y haber vuelto innecesaria la inversión de energía en obras más o menos monumentales, mientras que en otros podrían haber actuado como focos de resistencia en los que la imposición de las normas y de la cultura material del Imperio se diluyeron.

En cuanto al tramo de la red troncal, en la vía que atraviesa el tambo de Punta Balasto confluían tres importantes ramales. Uno de ellos, con rumbo sudoeste, conectaba con los conspicuos centros de Hualfín y Shincal (Raffino et al. 1985). Otro, hacia el sur, tras una estación en el tambo de Ingenio del Arenal, enlazaba con los distritos mineros de Capillitas Atajo y Andalgalá (González 1982: 333). El tercero ascendía hacia el sudeste, por la quebrada del río Pajanguillo hasta llegar al establecimiento de Nevados del Aconquija, con las estaciones intermedias de Pajanguillo, Becobel y Tambo Colorado.

En síntesis, la arrolladora dinámica de expansión del Estado incaico parece haber arrastrado, en ciertas oportunidades, el enfoque de las investigaciones arqueológicas en los Andes meridionales, otorgando un casi exclusivo protagonismo a las aspiraciones del Cusco y dejando en un oscuro segundo plano a los procesos históricos de las sociedades que poblaban las regiones incorporadas al Tawantinsuyu. Desde una óptica alternativa, en la que se privilegia el estudio de los procesos de cambio a partir de la posición de las sociedades dominadas, sostenemos que los intereses particulares de las élites políticas locales, la dinámica de los conflictos faccionales y el sistema de representaciones constituyeron factores activos que matizaron el modo en que la dominación estatal fue plasmada (González \& Tarragó 2005), articulando estrategias de negociación y resistencia. En el proceso de ocupación territorial no solo los planificadores cusqueños exhibieron una amplia flexibilidad para desplegar sus objetivos particulares. También las formaciones sociales abarcadas desarrollaron sus propias estrategias para no perder espacio dentro de las nuevas condiciones.

RECONOCIMIENTOS A todos los estudiantes, colaboradores e investigadores que aportaron su interés y esfuerzo a lo largo de tres décadas de trabajos arqueológicos en Yocavil. Luis González impulsó las investigaciones sobre la presencia incaica en el área. Catriel Greco, Sonia Lanzelotti, Mariela Tancredi y Raúl Doro colaboraron en la elaboración de diferentes ilustraciones que reproducimos en este artículo. A las autoridades y personal del Museo Etnográfico Juan B. Ambrosetti, del Museo de La Plata, del Museo de Antropología de la Universidad Nacional de Córdoba y del Museo de la Escuela de Antropología de la Universidad Nacional de Rosario. A los evaluadores anónimos y a los editores de la revista.

\section{NOTAS}

${ }^{1}$ Las calibraciones corresponden a la curva de calibración ShCal04 Southern Hemisphere Calibration (McCormac et al. 2004).

2 Los fechados considerados para este promedio son:

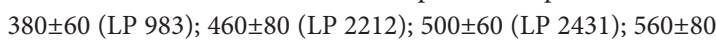
(LP 2239). 
${ }^{3}$ MAC: Museo de Antropología, Facultad de Filosofía y Humanidades, Universidad Nacional de Córdoba. MLP: Museo de La Plata, Facultad de Ciencias Naturales y Museo, Universidad Nacional de La Plata. MEjBA: Museo Etnográfico Juan B. Ambrosetti, Facultad de Filosofía y Letras, Universidad de Buenos Aires. MEAUnR: Museo de la Escuela de Antropología, Universidad Nacional de Rosario.

\section{REFERENCIAS}

Aldunate, C.; V. Castro \& V. Varela, 2003. Antes del Inka y después del Inka: paisajes y sacralidad en la puna de Atacama. Boletín de Arqueología PUCP 7: 9-26.

Bruch, C., 1911. Arqueología de las provincias de Tucumán y Catamarca. Revista del Museo de La Plata 19. Buenos Aires: Biblioteca Centenaria.

Carrara, M. T.; A. M. Lorandi, S. Renard \& M. Tarragó, 1960. Punta de Balasto. Investigaciones arqueológicas en el valle de Santa María 4: 13-51. Rosario: Instituto de Antropología, Universidad Nacional del Litoral.

CASTRO, V., 1992. Nuevos registros de la presencia Inka en la provincia de El Loa, Chile. Gaceta Arqueológica Andina 21: 139-154.

Fernández De Oviedo y VAldés, G., 1851-1855. Historia general y natural de las Indias, Islas y Tierra Firme del mar océano. Madrid: Real Academia de la Historia.

GonzÁlez de Prado, P., 1919 [1548]. Capítulos de una información de los servicios prestados por Pedro González de Prado, que entró en las provincias del Tucumán y Río de la Plata con Diego de Rojas, Felipe Gutiérrez y Nicolás de Heredia, y se señaló en la expedición de Francisco de Mendoza. En Gobernación del Tucumán. Probanzas de méritos y servicios de los conquistadores del Tucumán, tomo 1, R. Levillier, Dir., pp. 1-67. Madrid: Sucesores de Rivadeneyra.

GonzÁlez, A. R., 1982. Las provincias incas del antiguo Tucumán. Revista del Museo Nacional XLvi: 317-380. Lima: Museo Nacional.

GonZÁLEZ, C., 1996. El criterio monumentalista y su aplicación en la arquitectura inka de Chile central. Boletín Sociedad Chilena de Arqueología 23: 33-37.

González, L. R. \& M. N. Tarragó, 2004. Producción tecnológica e identidad durante el dominio incaico en el Noroeste Argentino. Boletín de Arqueología PUCP 8: 191-207.

GonzÁLEZ, L. R. \& M. N. TARragó, 2005. Vientos del sur. El valle de Yocavil (Noroeste Argentino) bajo la dominación incaica. Estudios Atacameños 29: 67-95.

GonzÁlez, L. R. \& T. PALACios, 1996. El volar es para los pájaros. Análisis técnico de dos piezas metálicas procedentes del valle de Santa María, pcia. de Catamarca. Arqueología 6: 10-25.

GonzÁLeZ, L. R., 1997. Arqueología y etnohistoria. Un caso de investigación arqueometalúrgica en el sur del valle de Yocavil, Noroeste Argentino. En Actas XIV Congreso Nacional de Arqueología Chilena, tomo 1, pp. 29-47. Copiapó: Museo Regional de Atacama.
González, L. R., 1999. Tambo feroz. Nuevos datos sobre el asentamiento de Punta de Balasto y la ocupación incaica en el sur del valle de Santa María (prov. de Catamarca). En Actas XII Congreso Nacional de Arqueología Argentina, tomo I, pp. 222-232. La Plata.

GONZÁLEZ, L. R., 2004. Bronces sin nombre. La metalurgia prehispánica en el Noroeste Argentino. Buenos Aires: Fundación CEPPA.

González, L. R; G. A. Gluzman, J. M. Estévez \& H. D. Buono, 2007. El Inca en el sur del valle de Yocavil. Investigaciones en el tambo de Punta de Balasto. En Actas XVI Congreso Nacional de Arqueología Argentina, tomo II, pp. 531-537. Jujuy.

Greco, C., 2012. Ms. Integración de datos arqueológicos, radiocarbónicos y geofísicos para la construcción de una cronología de Yocavil y alrededores. Tesis para optar al grado de Doctora en Arqueología, Facultad de Filosofía y Letras, Universidad de Buenos Aires.

Greco, C., 2014. La cronología del valle de Yocavil. Escalas, datos y resultados. Arqueología 20 Dossier: 11-37. Buenos Aires.

Hyslop, J., 1984. The Inka Road System. Nueva York: Academic Press.

KrisCAUtZKy, N., 1999. Arqueología del Fuerte Quemado de Yokavil. Catamarca: Dirección Provincial de Cultura.

LAfone Quevedo, S., 1902. Viaje á los Menhires é Intihuatana de Tafí y Santa María, en Octubre de 1898. Revista del Museo de La Plata XI: 3-8.

Liberani, I. \& J. HernándeZ, 1950 [1877]. Excursión arqueológica en los valles de Santa María, Catamarca. San Miguel de Tucumán: Instituto de Antropología.

Marchegiani, M. I., 2012. La variabilidad alfarera en el tambo de Punta de Balasto y la producción cerámica en Yocavil en la época de la dominación incaica (Catamarca, Noroeste Argentino). Arqueología 18: 77-100.

Marchegiani, M.; V. Palamarczuk \& A. Reynoso, 2009. Las urnas negro sobre rojo tardías de Yocavil (Noroeste Argentino). Reflexiones en torno al estilo. Boletín del Museo Chileno de Arte Precolombino 14 (1): 69-98.

Matienzo, J. DE, 1918 [2-1-1566]. Carta al rey, La Plata. En La Audiencia de Charcas, correspondencia de presidentes y oidores, volumen 1, R. Levillier, Dir., pp. 168-179. Madrid: Pueyo.

McCormac, F; A. Hogg, P. Blackwell, C. Buck, T. G Higham \& P. Reimer, 2004. ShCal04 Southern Hemisphere Calibration, 0-11.0 Cal Kyr BP. Radiocarbon 46 (3): 1087-1092.

Morris, C., 1988. Progress and prospect in the archaeology of the Inca. En Peruvian Prehistory, R. Keatinge, Ed., pp. 233-256. Cambridge: Cambridge University Press.

NARDI, R., 1979. El cacán, lengua de los diaguitas. Sapiens 3: 1-33. Nielsen, A. \& W. WALKer, 1999. Conquista ritual y dominación política en el Tawantinsuyu. El caso de Los Amarillos (Jujuy, Argentina). En Sed non satiata. Teoría social en la arqueología latinoamericana contemporánea, A. Zarankin \& F. Acuto, Eds., pp., 153-169. Buenos Aires: Ediciones del Tridente.

Orgaz, M., 2012. Chicha y aloja. Inkas y autoridades locales en el sector meridional del valle de Yocavil-Catamarca-Argentina. Surandino Monográfico, segunda sección del Prohal Monográfico II (2): 1-38. Buenos Aires. 
Orgaz, M., 2014. Un estudio funcional de las estructuras del sector local -V- del sitio Fuerte Quemado-Intihuatana. Estudios Antropología Historia 2: 75-97.

Palamarczuk, V. \& C. Greco. 2012. Estilo y tiempo. Un estudio sobre la cronología del estilo cerámico Famabalasto Negro Grabado del Noroeste Argentino mediante dataciones radiocarbónicas. Estudios Atacameños 43: 95-120.

Palamarczuk, V., 2002. Ms. Análisis cerámico de sitios del bajo de Rincón Chico. Valle de Yocavil, Provincia de Catamarca. Tesis para optar al grado de Licenciada en Ciencias Antropológicas con orientación en Arqueología, Facultad de Filosofía y Letras, Universidad de Buenos Aires, Argentina.

Palamarczuk, V., 2011. Un estilo y su época. El caso de la cerámica Famabalasto Negro Grabado del Noroeste Argentino. Oxford: British Archaeological Reports-Archaeopress.

Pärssinen, M., 1992. The Inca State and its political organization. Helsinki: Societas Historica Finlandiae.

Patterson, P., 1992. The Inca Empire. The formation and disintegration of a pre-capitalist State. Oxford: Berg.

Piossek Prebisch, T., 1984. Relación histórica de Calchaquí. Escrita por el misionero jesuita padre Hernando de Torreblanca en 1696. Buenos Aires: Ediciones Culturales Argentinas.

Quiroga, A., 1901. Ruinas calchaquíes, Fuerte Quemado. Anales de la Sociedad Científica Argentina 52: 235-243.

Raffino, R., 1981. Los Incas del Collasuyu. La Plata: Ramos.

Raffino, R.; R. Alvis, L. Baldini, D. Olivera \& M. Raviña, 1985. Hualfín, El Shincal, Watungasta. Tres casos de urbanización Inka en el N. O. Argentino. Cuadernos del INA 10: 425-455, Buenos Aires.

Reynoso, A. \& G. Pratolongo, 2008. Jaguares de nuevo. Consideraciones sobre la temática felínica en la iconografía cerámica del Período Tardío en Yocavil (Noroeste Argentino). Estudios Atacameños 35: 75-96.

Reynoso, A., 2009. El color y el fuego: excavaciones en la plaza de la cumbre de Rincón Chico (Provincia de Catamarca). Comechingonia 12: 75-90.

Reynoso, A; G. Pratolongo, V. Palamarczuk, M. Marchegiani \& M. S. GRIMOLDI, 2010. El calvario de Fuerte Quemado de Yocavil. Excavaciones en los torreones incaicos. En Actas del XVII Congreso Nacional de Arqueología Argentina, tomo IV: 1327-1332. Mendoza: Universidad Nacional de Cuyo.

Stingl, M., 2007. El imperio de los Incas. Esplendor y decadencia de los hijos del Sol. Buenos Aires: Losada.

Strube Erdmann, L., 1958. La ruta de Diego de Almagro en su viaje de exploración a Chile. Córdoba: Universidad Nacional de Córdoba.

Strube Erdmann, L., 1963. Vialidad imperial de los Incas. Serie Histórica 33. Córdoba: Universidad Nacional de CórdobaInstituto de Estudios Americanistas.

TArragó, M. N. \& L. R. GonzÁLeZ, 2004. Arquitectura social y ceremonial en Yocavil, Catamarca. Relaciones de la Sociedad Argentina de Antropología 29: 297-316.

Tarragó, M. N. \& L. R. González, 2005. Variabilidad de los modos arquitectónicos incaicos. Un caso de estudio en el valle de Yocavil (Noroeste Argentino). Chungara 37 (2): 129-143.

TARRAGÓ, M. N., 1984. El contacto hispano-indígena. La provincia de Chicoana. Runa 14: 143-185.

Tarragó, M. N., 2011. Poblados tipo pukara en Yocavil. El plano de Rincón Chico 1 (Catamarca, Argentina). Estudios Sociales del NOA (N. S.) 11: 1-29.

Tarragó, M. N.; L. R. González, P. Corvalán, R. Doro, M. ManAsiewicZ \& J. PeÑa, 1999. La producción especializada de alimentos en el asentamiento prehispánico tardío de Rincón Chico, provincia de Catamarca. Cuadernos del Instituto Nacional de Antropología y Pensamiento Latinoamericano 18: 409-427.

Vitry, C., 2007. La ruta de Diego de Almagro en el territorio argentino: un aporte desde la perspectiva de los caminos prehispánicos. Revista Escuela de Historia 6 (1): 325-351, Salta.

Williams, V., 2004. Poder estatal y cultura material en el Kollasuyu. Boletín de Arqueología PUCP 8: 209-246. 